ARTICLE

Received 18 Mar 2014 | Accepted 11 Jul 2014 | Published 19 Aug $2014 \quad$ DOl: 10.1038/ncomms5667

\title{
Molecular determinants of magnesium-dependent synaptic plasticity at electrical synapses formed by connexin36
}

\author{
Nicolás Palacios-Prado ${ }^{1,2}$, Sandrine Chapuis ${ }^{1}$, Alejandro Panjkovich ${ }^{3}$, Julien Fregeac ${ }^{1}$, James I. Nagy ${ }^{4}$ \\ \& Feliksas F. Bukauskas ${ }^{1}$
}

Neuronal gap junction (GJ) channels composed of connexin36 (Cx36) play an important role in neuronal synchronization and network dynamics. Here we show that $\mathrm{C} \times 36$-containing electrical synapses between inhibitory neurons of the thalamic reticular nucleus are bidirectionally modulated by changes in intracellular free magnesium concentration $\left(\left[\mathrm{Mg}^{2+}\right]_{\mathrm{i}}\right)$. Chimeragenesis demonstrates that the first extracellular loop of $\mathrm{C} \times 36$ contains a $\mathrm{Mg}^{2+}$-sensitive domain, and site-directed mutagenesis shows that the pore-lining residue D47 is critical in determining high $\mathrm{Mg}^{2+}$-sensitivity. Single-channel analysis of $\mathrm{Mg}^{2+}$-sensitive chimeras and mutants reveals that $\left[\mathrm{Mg}^{2+}\right]_{i}$ controls the strength of electrical coupling mostly via gating mechanisms. In addition, asymmetric transjunctional $\left[\mathrm{Mg}^{2+}\right]_{i}$ induces strong instantaneous rectification, providing a novel mechanism for electrical rectification in homotypic Cx36 GJs. We suggest that $\mathrm{Mg}^{2+}$-dependent synaptic plasticity of $\mathrm{C} \times 36$-containing electrical synapses could underlie neuronal circuit reconfiguration via changes in brain energy metabolism that affects neuronal levels of intracellular ATP and $\left[\mathrm{Mg}^{2+}\right]_{\mathrm{i}}$.

\footnotetext{
${ }^{1}$ Dominick P. Purpura Department of Neuroscience, Albert Einstein College of Medicine, Bronx, New York 10461, USA. ${ }^{2}$ Grass Laboratory, Marine Biological Laboratory, Woods Hole, Woods Hole, Massachusetts 02543, USA. ${ }^{3}$ European Molecular Biology Laboratory, Hamburg Outstation, 22603 Hamburg, Germany. ${ }^{4}$ Department of Physiology, University of Manitoba, Winnipeg, Manitoba, Canada R3E 0J9. Correspondence and requests for materials should be addressed to N.P.-P. (email: nicolas.palacios-prado@phd.einstein.yu.edu) or to F.F.B. (email: feliksas.bukauskas@einstein.yu.edu).
} 
M agnesium is the second most abundant intracellular cation after potassium, and is a critical cofactor in many enzymatic reactions involving energy metabolism. Magnesium is highly concentrated in cellular organelles, such as mitochondria, nucleus and endoplasmic reticulum, and it binds to several ionic cytoplasmic constituents. Importantly, phosphonucleotides, such as ATP, bind magnesium ions $\left(\mathrm{MgATP}^{-}\right)$and the enzymatic hydrolysis of their phosphate groups depends on this interaction ${ }^{1}$. Therefore, the intracellular concentration of free magnesium $\left(\left[\mathrm{Mg}^{2+}\right]_{\mathrm{i}}\right)$ is closely related to cell bioenergetics and is expected to vary according to the state of cellular metabolism and levels of intracellular $\mathrm{ATP}^{2}$. Resting $\left[\mathrm{Mg}^{2}{ }^{+}\right]_{\mathrm{i}}$ is less than $10 \%$ of total cellular magnesium, and it ranges from 0.2 to $3.5 \mathrm{mM}$ in neurons depending on cell type and species ${ }^{3-5}$. Under physiological conditions, depolarization triggers an increase of $\left[\mathrm{Mg}^{2+}\right]_{\mathrm{i}}$ in sensory neurons ${ }^{6}$, while glutamate exposure induces a $\left[\mathrm{Mg}^{2+}\right]_{\mathrm{i}}$ surge in forebrain and hippocampal neurons ${ }^{7,8}$. More recently, it was shown that activation of a nitric oxide signalling pathway can also trigger an increase of $\left[\mathrm{Mg}^{2+}\right]_{\mathrm{i}}$ in hippocampal neurons ${ }^{9}$. Moreover, enhanced $\left[\mathrm{Mg}^{2+}\right]_{\mathrm{i}}$ can be expected with a reduction in the levels of ATP during periods of waking and hyperactivity ${ }^{10}$. Conversely, reduction in $\left[\mathrm{Mg}^{2+}\right]_{\mathrm{i}}$ can be expected with an increase in ATP levels during glucose or lactate exposure ${ }^{11}$ and during the first hours of sleep ${ }^{10}$. In pathological conditions, early onset of ischaemic cell death is mainly due to the inability of mitochondria to produce ATP, resulting in the failure to regulate transmembrane ion gradients ${ }^{12}$, which impacts $\left[\mathrm{Mg}^{2+}\right]_{\mathrm{i}}$. Long-lasting elevation in brain $\left[\mathrm{Mg}^{2+}\right]_{\mathrm{i}}$ occurs in some acute and chronic brain pathologies such as hypoxia/ischaemia ${ }^{13,14}$ and in patients with schizophrenia ${ }^{15}$. In contrast, $\left[\mathrm{Mg}^{2+}\right]_{\mathrm{i}}$ is reduced after traumatic brain injury ${ }^{16,17}$ and in patients with Parkinson ${ }^{18}$, Alzheimer ${ }^{19}$, multiple sclerosis ${ }^{20}$, amyotrophic lateral sclerosis ${ }^{21}$, chronic migraine ${ }^{22}$ and mitochondrial diseases ${ }^{23}$.

Electrical synapses are specialized intercellular junctions formed by clusters of gap junction (GJ) channels that allow bidirectional electrotonic signalling between neurons. Many roles for electrical synapses have been documented, such as synchronization and coordination of neuronal networks ${ }^{24}$, memory formation $^{25}$ and lateral excitation in olfactory glomeruli ${ }^{26}$. GJ channels are formed by the connexin $(\mathrm{Cx})$ and innexin gene families in vertebrates and invertebrates, respectively. Six Cx (or innexin) proteins oligomerize into a pore-forming hemichannel (HC), and the docking of two HCs contributed by adjacent cells forms a GJ channel. The docking of HCs from apposing cells containing the same Cx type results in homotypic GJs, while the docking of HCs containing different Cxs results in heterotypic GJs. Sensitivity of junctional conductance $\left(g_{\mathrm{j}}\right)$ to transjunctional voltage $\left(V_{\mathrm{j}}\right)$ is a common property of all GJs. Each apposed/ junctional $\mathrm{HC}$ (aHC) has two distinct $V_{\mathrm{j}}$-sensitive gates that are responsible for the steady-state $g_{\mathrm{j}}-V_{\mathrm{j}}$ relationship $\left(g_{\mathrm{j}, \mathrm{ss}}-V_{\mathrm{j}}\right)$. This relationship is typically symmetric for either polarity of $V_{\mathrm{j}}$ in homotypic junctions ${ }^{27}$, but asymmetric in heterotypic junctions where aHCs have $V_{\mathrm{j}}$ sensitivity and/or single-channel conductance differences, which leads to an asymmetry in electrical signal transfer and metabolic communication ${ }^{28,29}$. An instantaneous $g_{\mathrm{j}}-V_{\mathrm{j}}$ relationship $\left(g_{\mathrm{j} \text {,inst }}-V_{\mathrm{j}}\right)$, however, is more relevant with respect to electrical synapses since neuronal membrane potential fluctuates in the ms time scale during action potentials. Many electrical synapses rectify instantaneously ${ }^{30-33}$; that is, electrical signals are preferentially transmitted anterogradely or retrogradely. Electrical synapses between neurons in the mammalian central nervous system (CNS) are typically formed by connexin $36(\mathrm{Cx} 36)^{34}$, which is commonly expressed throughout the $\mathrm{CNS}^{34,35}$. Modulation of electrical synapses can occur by different factors such as phosphorylation 36,37 , changes in $\mathrm{pH}^{38}$ and exposure to lipophilic molecules ${ }^{39}$. Interestingly, Cx36-containing electrical synapses can undergo activity-dependent long-term depression ${ }^{40}$ or CaMKII- and PKA-dependent long-term potentiation ${ }^{41,42}$

We recently reported a novel $\mathrm{Mg}^{2}{ }^{+}$-dependent form of electrical synaptic plasticity between neurons of the trigeminal mesencephalic nucleus (MesV) and in heterologous expression systems transfected with Cx36 (ref. 43). We showed that the strength of electrical synaptic transmission is augmented or reduced by low or high $\left[\mathrm{Mg}^{2+}\right]_{\mathrm{i}}$, respectively. The $g_{\mathrm{j}}$ of GJs formed of Cxs 26, 30.2, 32, 36, 43, 45, 47 and 57 expressed in HeLa cells was reduced by increasing $\left[\mathrm{Mg}^{2+}\right]_{\mathrm{i}}$, whereas lowering $\left[\mathrm{Mg}^{2+}\right]_{\mathrm{i}}$ increased $g_{\mathrm{j}}$ only in Cx36 expressing cells, indicating that Cx36 GJs are strongly inhibited by normal/resting $\left[\mathrm{Mg}^{2+}\right]_{\mathrm{i}}$. We also demonstrated that $\mathrm{Mg}^{2}+$ ions are permeable to $\mathrm{Cx} 36$ GJs and an effect of $\mathrm{Mg}^{2+}$ on $g_{\mathrm{j}}$ is fully reversible ${ }^{43}$.

Here, we show that electrical synapses formed by $\mathrm{Cx} 36$ in the thalamic reticular nucleus (TRN) are also bidirectionally modulated by changes in $\left[\mathrm{Mg}^{2+}\right]_{\mathrm{i}}$ and that an altered $\mathrm{Mg}-\mathrm{ATP}$ equilibrium can trigger $\mathrm{Mg}^{2+}$-dependent plasticity of neuronal electrical coupling. We sought to locate the molecular domains of Cx36 GJ channels that contribute to such unusually high sensitivity to $\left[\mathrm{Mg}^{2+}\right]_{\mathrm{i}}$ using chimeragenesis and site-directed mutagenesis. Our data show that a negatively charged aspartate (D47), located in the first extracellular loop (E1), is responsible for high $\mathrm{Mg}^{2+}$-sensitivity. Single-channel analysis of chimeras $(\mathrm{CH})$ reveals that changes in $\left[\mathrm{Mg}^{2+}\right]_{i}$ affect the voltagedependent gating of channels without changing the singlechannel conductance. We also found that $\left[\mathrm{Mg}^{2+}\right]_{\mathrm{i}}$ modulates the $g_{\text {j,inst }}-V_{\mathrm{j}}$ dependence of Cx36 GJs by producing a hyperbolic $g_{\mathrm{j}, \text { inst }}-V_{\mathrm{j}}$ relationship that is unique to Cx36 GJs. Previously, we showed that asymmetry in the transjunctional $\left[\mathrm{Mg}^{2+}\right]_{i}$ results in an asymmetry of steady-state $g_{\mathrm{j}}\left(g_{\mathrm{j}, \mathrm{ss}}\right)$ dependence on $V_{\mathrm{j}}$ (ref. 43). We now demonstrate that asymmetry in the transjunctional $\left[\mathrm{Mg}^{2+}\right]_{i}$ results in an asymmetric $g_{j, \text { inst }}-V_{j}$ relationship of homotypic Cx36 GJ channels. Hence, the intercellular gradient of divalent cations, such as $\mathrm{Mg}^{2+}$, is a novel mechanism that can generate instantaneous rectification in homotypic Cx36 GJs. In addition, we show that the second extracellular loop (E2) is an important molecular component that contributes to the incompatibility between neuronal $\mathrm{Cx} 36$ and astrocytic $\mathrm{Cx} 43$ HCs to dock and form functional heterotypic GJs.

\section{Results}

Electrical synapses in the TRN are modulated by $\left[\mathrm{Mg}^{2+}\right]_{\mathrm{i}}$. To test whether native electrical synapses expressing Cx36 are sensitive to changes in $\left[\mathrm{Mg}^{2+}\right]_{i}$, we used a BAC transgenic mouse line $(\mathrm{Tg}(G j d 2-E G F P) J M 16 \mathrm{Gsat} / \mathrm{Mmucd})^{44}$, in which the expression of the enhanced green fluorescent protein (EGFP) reporter gene is driven by the promoter of Cx36 and expression of the endogenous Cx36 protein is left intact. In Gjd2-EGFP mice, one can easily identify EGFP-positive neurons, facilitating the selection of adjacent pairs of electrically coupled neurons for electrophysiological analysis. The TRN was chosen for examination due to its relatively high incidence of electrical coupling ${ }^{45}$. It is a diencephalic layer of GABAergic interneurons that forms a capsule around the ventrobasal complex of the thalamus, and plays an important role in switching states of arousal and consciousness ${ }^{46}$. Acute horizontal slices of mouse thalamus were used for confocal fluorescence imaging of the TRN (Fig. 1a,b) and for measuring $g_{j}$ using a dual whole-cell patch clamp (Fig. 1c) in pairs of neurons displaying EGFP fluorescence (Fig. 1d). From a total of 57 neuronal pairs recorded, 18 pairs were electrically coupled (31.6\%). The intrinsic firing properties (Fig. 1e) and attenuated evoked responses (Supplementary Fig. 1) 

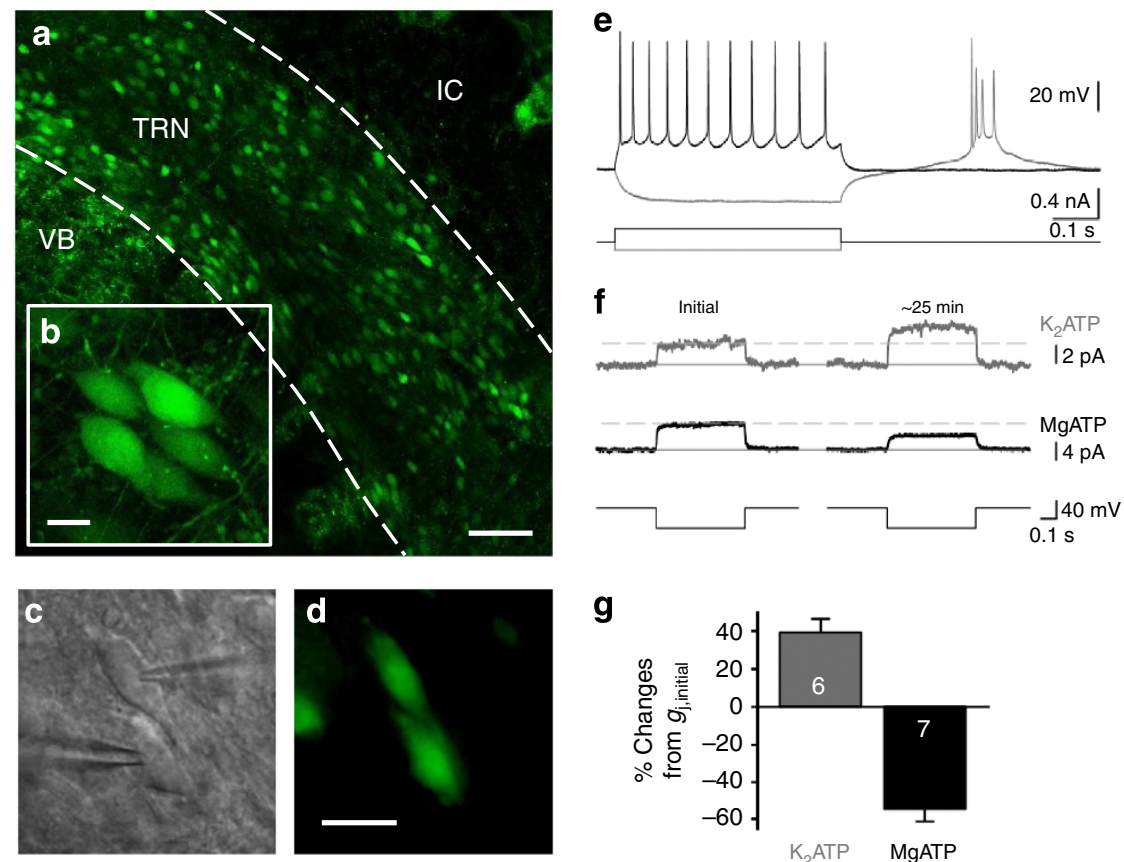

Figure 1 | Magnesium-dependent plasticity of electrical synaptic transmission between TRN neurons. (a,b) Confocal fluorescence images of horizontal brain slices from a Gjd2-EGFP transgenic mouse showing TRN interneurons expressing EGFP driven by Cx36 promoter. VB, ventrobasal nucleus of the Thalamus; IC, internal capsule. Scale bars correspond to 100 (a) and $10(\mathbf{b}) \mu \mathrm{m}$. (c,d) IR-DIC (c) and fluorescence (d) images of an electrically coupled pair of TRN neurons during dual whole-cell patch clamp. Scale bar, $20 \mu \mathrm{m}$. (e) Current-clamp recordings from a TRN neuron showing typical spiking and rebound burst behaviour; voltage traces were recorded during $0.5 \mathrm{~s}$ current steps of -100 (grey) or $200 \mathrm{pA}$ (black). (f) Voltage-clamp recordings showing averaged transjunctional current traces (10-15 averaged traces) obtained soon after patch openings (initial; left) and after $\sim 25$ min of recording (right) for low $\mathrm{Mg}^{2+}\left(\mathrm{K}_{2} \mathrm{ATP}\right.$, top) and high $\mathrm{Mg}^{2+}(\mathrm{MgATP}$, bottom) conditions; current traces were recorded during $0.5 \mathrm{~s}$ transjunctional voltage steps of $-40 \mathrm{mV}$. (g) Mean percentage changes of junctional conductance $\left(g_{j}\right)$ from initial values after $\sim 25$ min from patch openings with pipette solutions containing $7 \mathrm{mM}$ of $\mathrm{K}_{2}$ ATP (grey) or MgATP (black). Numbers of cell pairs are indicated within columns, and error bars correspond to s.e.m.

of electrically coupled EGFP-expressing neurons were similar to those previously reported ${ }^{45}$. To reduce or increase $\left[\mathrm{Mg}^{2+}\right]_{\mathrm{i}}$, we used pipette solutions with $\mathrm{K}_{2} \mathrm{ATP}$ or MgATP, respectively, as previously shown ${ }^{2,43}$. Pipette solutions with $\mathrm{K}_{2}$ ATP $(7 \mathrm{mM})$ showed a $\sim 40 \%$ increase in $g_{j}$ after $25 \mathrm{~min}$ of recording (Fig. 1f,g). Conversely, solutions with $\operatorname{MgATP}(7 \mathrm{mM})$ showed a $\sim 50 \%$ decrease in $g_{j}$ after $25 \mathrm{~min}$ of recording (Fig. 1f,g). Therefore, inhibitory interneurons from the TRN showed a significant bidirectional $\mathrm{Mg}^{2+}$-dependent modulation of $g_{\mathrm{j}}$, in a similar manner as reported for excitatory neurons from the $\mathrm{MesV}^{43}$

E1 contains a pore-lining $\mathbf{M g}^{\mathbf{2}+}$-sensitive domain. To locate the position of putative $\mathrm{Mg}^{2+}$-sensitive domain/s in Cx36, we performed structure-function studies by assessing $g_{\mathrm{j}}$ in response to $\left[\mathrm{Mg}^{2+}\right]_{\mathrm{i}}$ in pairs of RIN cells expressing $\mathrm{Cx} 36 / \mathrm{Cx} 43 \mathrm{CH}$ and mutants with single amino acid substitutions. We selected $\mathrm{Cx} 43$ because it shows a higher single-channel conductance $\left(\gamma_{\text {open }}\right.$; $\sim 110 \mathrm{pS}$ (ref. 47)), a higher $V_{\mathrm{j}}$-gating sensitivity and a lower sensitivity to changes in $\left[\mathrm{Mg}^{2+}\right]_{i}^{43}$, relative to $\mathrm{Cx} 36$. $\mathrm{CH}$ were generated by sequential exchange of corresponding domains of Cx36 and Cx43 using a modified version of the 'sticky feet' protocol $^{48}$ (See Methods and Supplementary Figs 2 and 3). We swapped selected domains at the expected interface between membrane and extracellular domains, and generated a total of sixteen $\mathrm{CH}$ from which eight formed junctional plaques (all $\mathrm{CH}$ were tagged with EGFP at the $\mathrm{C}$ terminus (CT) and expressed in RIN cells) and only four (CH1-CH4) formed functional channels exhibiting electrical cell-cell coupling (Fig. 2). We studied sensitivity to $\left[\mathrm{Mg}^{2+}\right]_{\mathrm{i}}$ by measuring $g_{\mathrm{j}}$ at the beginning of the

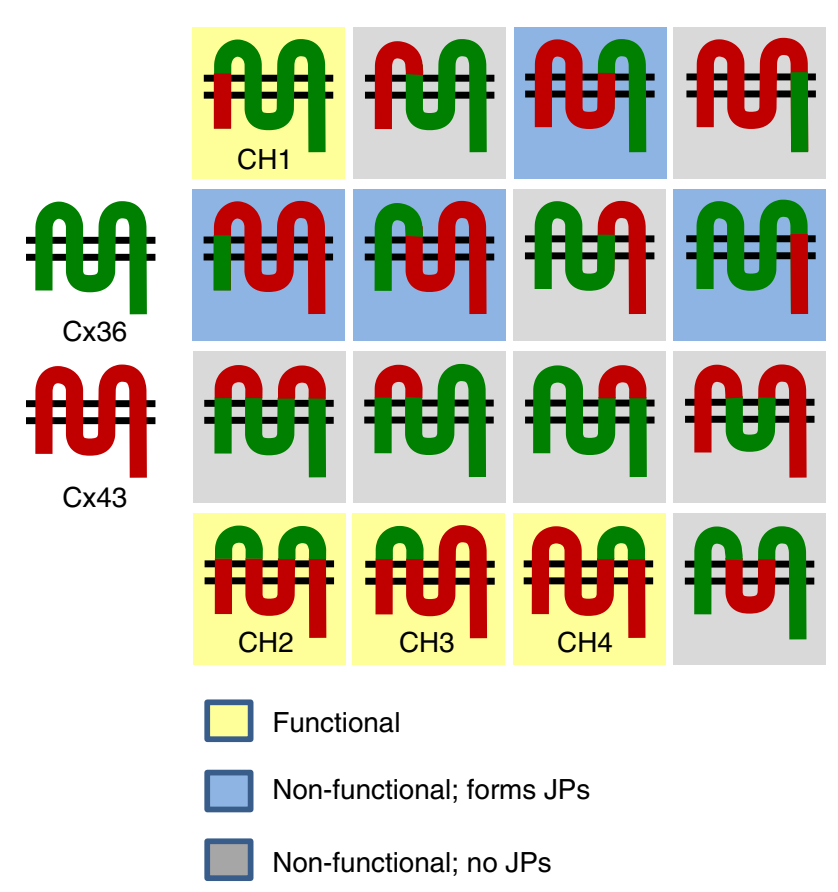

Figure 2 | All generated $\mathbf{C x 3 6 / C x 4 3 ~} \mathbf{C H}$. $\mathrm{CH}$ were generated from $\mathrm{Cx36}$ (green) and $\mathrm{C} \times 43$ (red). $\mathrm{CH}$ that form functional channels and junctional plaques (JPs) are shown in yellow background. Functional $\mathrm{CH}$ are named from $\mathrm{CH} 1$ to $\mathrm{CH} 4$. $\mathrm{CH}$ that form JPs but do not exhibit electrical cell-cell coupling are shown in blue background. $\mathrm{CH}$ that do not form JPs or exhibit electrical cell-cell coupling are shown in grey background. 
recording $\left(g_{\text {j,initial }}\right)$ and the ratio of $g_{\mathrm{j}, \text { final }} / g_{\text {,initial }}$, where $g_{\mathrm{j}, \text { final }}$ is the $g_{j}$ value at the steady-state level (after $\sim 25 \mathrm{~min}$ ), using pipette solutions with low or high free $\mathrm{Mg}^{2}+$ concentrations; $\left[\mathrm{Mg}^{2+}\right]_{\mathrm{p}}=0.01$ or $5 \mathrm{mM}$. Cell pairs with approximately the same size of junctional plaques were used to study wild-type and chimeric GJs. The $\mathrm{Mg}^{2+}$ sensitivity of homotypic GJs formed by $\mathrm{CH} 1$ (see Supplementary Fig. 4 for amino acid sequence of functional $\mathrm{CH}$ ), in which the NT and first transmembrane domain (M1) of Cx36 was replaced by those of $\mathrm{Cx} 43$, was similar to the $\mathrm{Mg}^{2+}$-sensitivity of Cx36 (Fig. 3). Homotypic GJs formed by $\mathrm{CH} 2$ or $\mathrm{CH} 3$, in which $\mathrm{E} 1$ of $\mathrm{Cx} 43$ was replaced by $\mathrm{E} 1$ of $\mathrm{Cx} 36$, showed $\mathrm{Mg}^{2}+$ sensitivity similar to that of Cx36 GJs (Fig. 3). GJs formed by $\mathrm{CH} 4$, in which only $\mathrm{E} 2$ of $\mathrm{Cx} 43$ was replaced by E2 of $\mathrm{Cx} 36$, showed no changes in sensitivity to $\mathrm{Mg}^{2+}$ and was similar to that of $\mathrm{Cx} 43$ GJs (Fig. 3). Altogether, results from $\mathrm{Cx} 36 / \mathrm{Cx} 43$ $\mathrm{CH}$ indicate that $\mathrm{E} 1$ contains a $\mathrm{Mg}^{2+}$-sensitive domain that can be transferred between Cxs, and that NT, M1 and E2 are not involved in $\mathrm{Mg}^{2+}$-sensitivity.

D47 is critical for determining high sensitivity to $\left[\mathrm{Mg}^{2+}\right]_{\mathbf{i}}$. To locate region/s in E1 that may be responsible for the difference in $\mathrm{Mg}^{2}+$ sensitivity between $\mathrm{Cx} 36$ and $\mathrm{Cx} 43$, we generated single amino acid substitutions in non-conserved charged residues of Cx36 and Cx43 (Supplementary Fig. 5). Mutation M52K and $\mathrm{V} 54 \mathrm{D}$ in Cx36, and E62N in Cx43 had no effect on $\mathrm{Mg}^{2+}$ sensitivity. In contrast, GJs formed of $\mathrm{Cx} 36^{\star} \mathrm{D} 47 \mathrm{G}$ lost sensitivity to resting/initial $\left[\mathrm{Mg}^{2+}\right]_{\mathrm{i}}$, while GJs formed of $\mathrm{Cx} 43^{\star} \mathrm{G} 46 \mathrm{D}$ gained sensitivity to resting/initial $\left[\mathrm{Mg}^{2+}\right]_{\mathrm{i}}$ (Fig. 3). Position D47 in Cx36 corresponds to position G46 in Cx43. Moreover, GJs formed of $\mathrm{CH} 33^{*} \mathrm{D} 47 \mathrm{G}$ lost sensitivity to resting/initial $\left[\mathrm{Mg}^{2+}\right]_{\mathrm{i}}$ (Fig. 3). In summary, these data demonstrate that E1 contains a $\mathrm{Mg}^{2}{ }^{+}$-sensitive domain in which the D47 residue is critical to determine the uniquely high sensitivity of $\mathrm{Cx} 36 \mathrm{GJ}$ channels to
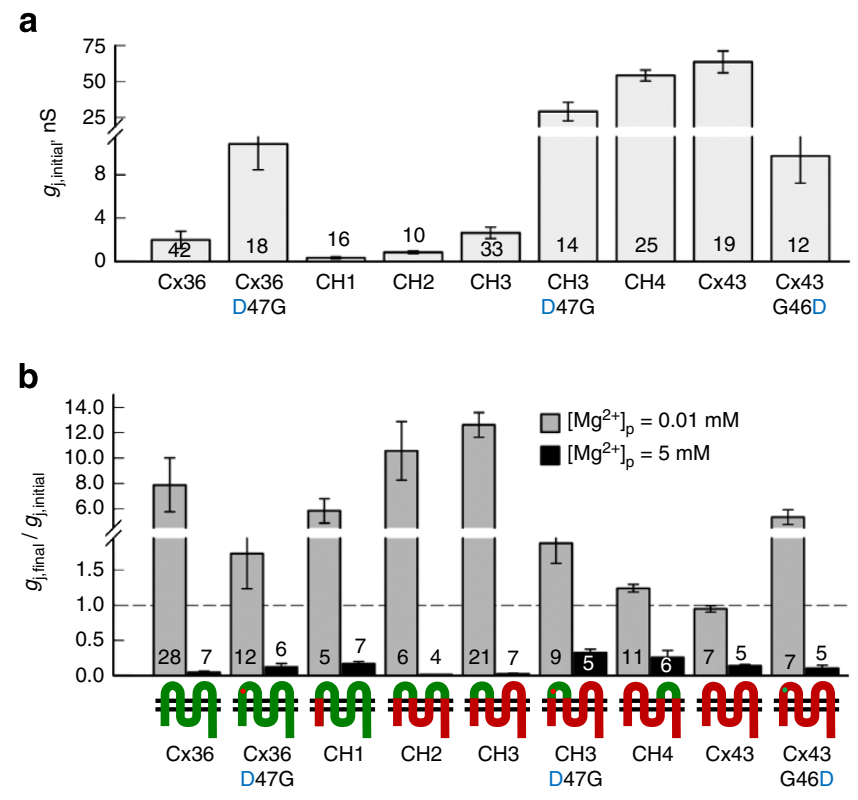

Figure 3 | Differences in sensitivity to $\left[\mathrm{Mg}^{2+}\right]_{\mathrm{i}}$ between $\mathrm{Cx36/Cx43} \mathrm{CH}$ and mutants. Experiments were performed in pairs of RIN cells expressing $\mathrm{C} \times 36$ (green), $\mathrm{C} \times 43$ (red), $\mathrm{C} \times 36 / \mathrm{C} \times 43 \mathrm{CH}(\mathrm{CH} 1-\mathrm{CH} 4)$ and amino acid substitutions (D47G or G46D). (a) Mean transjunctional conductance measured soon after patch opening $\left(g_{\mathrm{j}, \text { initial }}\right)$. (b) Mean $g_{\mathrm{j}}$ (normalized to initial $g_{\mathrm{j}}$ value) measured after $\sim 25$ min using pipette solutions containing $0.01 \mathrm{mM}$ (grey) or $5 \mathrm{mM}$ (black) free $\mathrm{Mg}^{2+}\left(\left[\mathrm{Mg}^{2+}\right]_{p}\right)$. The dotted line marks the value of normalized $g_{\mathrm{j}}$ equal to 1 . Total numbers of cell pairs are indicated within columns, and error bars correspond to s.e.m.
$\mathrm{Mg}^{2+}$, and that insertion of this single residue in $\mathrm{Cx} 43$ confers high sensitivity to $\mathrm{Mg}^{2+}$.

The $\gamma_{\text {open }}$ of $\mathrm{Cx} 36 / \mathrm{Cx} 43 \mathrm{CH}$ is not affected by $\left[\mathrm{Mg}^{2+}\right]_{\mathrm{i}}$. The $\gamma_{\text {open }}$ of Cx36 GJ channels remains uncertain due to its very low conductance ${ }^{49,50}$. For similar reasons, we were unable to examine with sufficient resolution the effects of $\left[\mathrm{Mg}^{2+}\right]_{i}$ on single $\mathrm{Cx} 36$ GJ channels. However, the effect of $\left[\mathrm{Mg}^{2+}\right]_{\mathrm{i}}$ at the single-channel level was amenable to analysis in $\mathrm{Cx} 43$-based $\mathrm{CH}$ and mutants, which exhibited $\gamma_{\text {open }}$ s similar to that of $\mathrm{Cx} 43 \mathrm{GJs}$. We found that $\gamma_{\text {open }}$ of $\mathrm{CH} 3$ remained unchanged when $\left[\mathrm{Mg}^{2+}\right]_{\mathrm{p}}=0.01$ and $5 \mathrm{mM}$ (Fig. 4a,e). These results are in agreement with our hypothesis that $\left[\mathrm{Mg}^{2+}\right]_{\mathrm{i}}$ controls electrical transmission mostly via gating mechanisms, as we previously suggested using a stochastic 16-state of GJ channels ${ }^{43}$. Furthermore, $\gamma_{\text {open }}$ of homotypic $\mathrm{CH} 3{ }^{\star} \mathrm{D} 47 \mathrm{G}$ and $\mathrm{CH} 4 \mathrm{GJs}$, both with low sensitivity to $\mathrm{Mg}^{2+}$ compared with that of $\mathrm{CH} 3 \mathrm{GJs}$, was also similar to $\gamma_{\text {open }}$ of Cx43 and remained unchanged in $\left[\mathrm{Mg}^{2+}\right]_{\mathrm{p}}=0.01$ and $5 \mathrm{mM}$ (Fig. 4b,c,e and Supplementary Fig. 6). In addition, $\gamma_{\text {open }}$ of $\mathrm{Cx} 43^{\star} \mathrm{G} 46 \mathrm{D}$ GJs remained close to that of $\mathrm{Cx} 43$ at high and low $\left[\mathrm{Mg}^{2+}\right]_{\mathrm{p}}$ (Fig. 4d,e). Homotypic GJs formed by $\mathrm{CH} 3$, $\mathrm{CH} 3{ }^{\star} \mathrm{D} 47 \mathrm{G}, \mathrm{CH} 4$ and $\mathrm{Cx} 43^{\star} \mathrm{G} 46 \mathrm{D}$ did not show $I_{\mathrm{j}}$ rectification at the single-channel level. Thus, $\mathrm{Mg}^{2+}$-dependent changes in $g_{\mathrm{j}}$ for these three $\mathrm{CH}$ and $\mathrm{Cx} 43$ most likely are defined by differences in $\mathrm{Mg}^{2+}$-binding affinity and its effects on gating, but not by changes in $\gamma_{\text {open }}$.

$\left[\mathrm{Mg}^{2+}\right]_{\mathrm{i}}$ affects $\boldsymbol{g}_{\mathrm{j}}$ via gating mechanisms. $\mathrm{CH} 3$ channels possess the $\mathrm{Mg}^{2+}$-sensitive E1 domain of $\mathrm{Cx} 36$ (Figs 2 and 3) and the high $\gamma_{\text {open }}$ is similar to that of $\mathrm{Cx} 43$ (Fig. 4), which allows for the analysis of $\mathrm{Mg}^{2+}$-dependent plasticity at the single-channel level. We studied $g_{\mathrm{j}}$ and its dependence on $V_{\mathrm{j}}$ in pairs of weakly coupled RIN cells expressing homotypic $\mathrm{CH} 3$ GJs. We measured $g_{\mathrm{j}, \mathrm{ss}}-V_{\mathrm{j}}$ relationships using $V_{\mathrm{j}}$ ramps from 0 to +90 and $-90 \mathrm{mV}$ in amplitude and $30 \mathrm{~s}$ in duration (Fig. 5a, top trace). Under high $\left[\mathrm{Mg}^{2+}\right]_{\mathrm{p}}$, there was a relatively fast run-down of $g_{\mathrm{j}}$ in CH3 GJs, thus $g_{\mathrm{j}}-V_{\mathrm{j}}$ plots from four consecutive measurements show different $g_{j}$ s at the beginning of each ramp (Fig. $5 \mathrm{a}-\mathrm{c}$ ). The initial $g_{\mathrm{j}}$ was $\sim 3.8 \mathrm{nS}$, corresponding to $\sim 33$ open $\mathrm{CH} 3 \mathrm{GJ}$ channels (Fig. 5a,c). Three minutes later, only one GJ channel was open during the fourth $V_{\mathrm{j}}$ ramp (red traces in Fig. 5a,c). To study the effects of $\mathrm{Mg}^{2+}$ occupancy inside the pore on $V_{\mathrm{j}}$ gating, a transjunctional gradient of $\left[\mathrm{Mg}^{2+}\right]_{i}$ was created by having different $\left[\mathrm{Mg}^{2+}\right]_{\mathrm{p}}$ (Fig. 5d); under these conditions, relative positivity or negativity on the side with higher $\left[\mathrm{Mg}^{2+}\right]_{i}$ should increase or reduce $\mathrm{Mg}^{2+}$ occupancy, respectively. The transjunctional asymmetry in $\left[\mathrm{Mg}^{2+}\right]_{i}$ resulted in strong asymmetric $g_{\mathrm{j}, \mathrm{ss}}-V_{\mathrm{j}}$ dependence measured using $V_{\mathrm{j}}$ ramps (Fig. 5e). At the single-channel level, negative $V_{\mathrm{j}}$ steps applied in the cell with lower $\left[\mathrm{Mg}^{2+}\right]_{\mathrm{i}}$ facilitated closing events, while positive $V_{\mathrm{j}}$ steps facilitated opening events (Fig. 5f). The $\gamma_{\text {open }}$ of CH3 GJ channels remained at $\sim 115 \mathrm{pS}$ regardless of the $V_{\mathrm{j}}$ polarity and $\mathrm{Mg}^{2+}$ occupancy (Fig. 5g,h). These results indicate that an increase in $\mathrm{Mg}^{2+}$ concentration inside the pore tends to close $V_{\mathrm{j}}$-sensitive gates.

Transjunctional asymmetry of $\left[\mathrm{Mg}^{2+}\right]_{i}$ induces rectification. To determine whether $\left[\mathrm{Mg}^{2+}\right]_{\mathrm{i}}$ affects $\gamma_{\text {open }}$ of $\mathrm{Cx} 36 \mathrm{GJ}$ channels in a $V_{\mathrm{j}}$-dependent manner, we examined the $g_{\mathrm{j} \text {,inst }}-V_{\mathrm{j}}$ relationship at different $\left[\mathrm{Mg}^{2+}\right]_{\mathrm{i}}$. The $g_{\mathrm{j} \text {,inst }}-V_{\mathrm{j}}$ dependence is relevant to the behaviour of electrical synapses, because $V_{\mathrm{j}}$ generated in neurons arises mostly from action potentials with fast (milliseconds) oscillatory changes in the membrane potential. Instantaneous macroscopic $I_{j} s\left(I_{j, \text { inst }}\right)$ mainly reflect the dependence of $\gamma_{\text {open }}$ on $V_{\mathrm{j}}$ in the absence of $V_{\mathrm{j}}$-dependent gating. Thus, we measured 

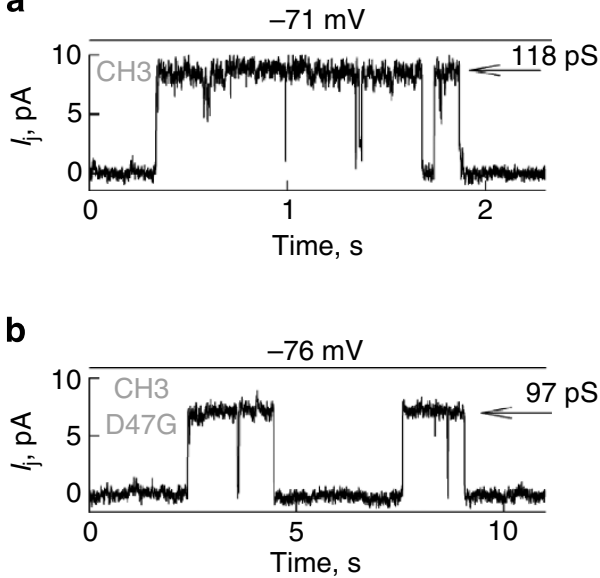

C

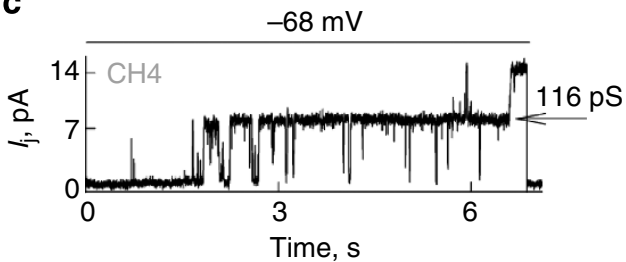

d

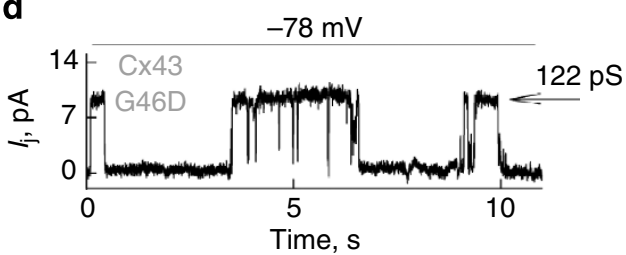

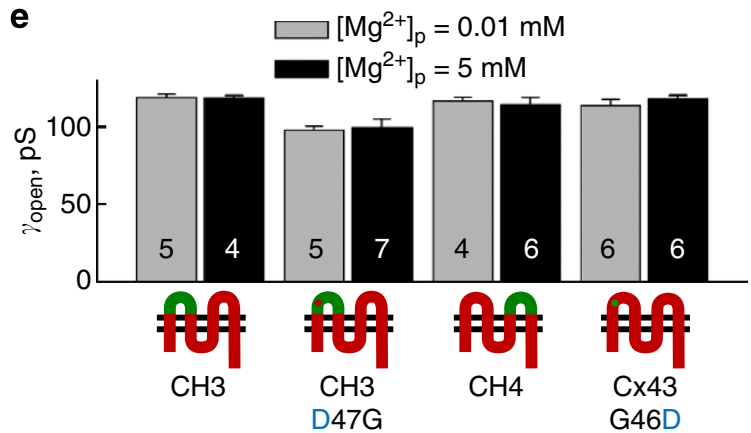

Figure 4 | Effect of $\left[\mathrm{Mg}^{2+}\right]_{\mathrm{i}}$ on single-channel conductance from homotypic GJs formed by CH3, CH3*D47G, CH4 or Cx43*G46D.

(a-d) Transjunctional current $\left(I_{j}\right)$ recordings of single-channel events obtained at indicated $V_{j} s$ (top) and using $\left[\mathrm{Mg}^{2}+\right]_{p}=0.01 \mathrm{mM}$. Numbers attached to arrows show single-channel conductances at the open state $\left(\gamma_{\text {open }}\right)$. (e) Averaged $\gamma_{\text {open }}$ for homotypic GJs formed by $\mathrm{CH} 3, \mathrm{CH} 3^{\star} \mathrm{D} 47 \mathrm{G}, \mathrm{CH} 4$ and $\mathrm{C} \times 43^{\star} \mathrm{G} 46 \mathrm{D}$ using $\left[\mathrm{Mg}^{2+}\right]_{\mathrm{p}}=0.01$ (grey) or 5 (black) $\mathrm{mM}$. Total numbers of cell pairs are indicated within columns, and error bars correspond to s.e.m.

steady-state and instantaneous $g_{\mathrm{j}}-V_{\mathrm{j}}$ dependencies at different $\left[\mathrm{Mg}^{2+}\right]_{\mathrm{i}}$ by using different $V_{\mathrm{j}}$ protocols (Fig. 6a,b). We found that under high $\left[\mathrm{Mg}^{2+}\right]_{\mathrm{i}}$, the $g_{\mathrm{j} \text {,inst }}$ (normalized to $g_{\mathrm{j}}$ value at zero $V_{\mathrm{j}}$ ) of Cx36 GJs increased while the $g_{\mathrm{j}, \mathrm{ss}}$ decreased by increasing $V_{\mathrm{j}} \mathrm{s}$ for both polarities (Fig. 6c, top panel). Low $\left[\mathrm{Mg}^{2+}\right]_{\mathrm{i}}$ fully eliminated or strongly reduced instantaneous and steady-state $g_{\mathrm{j}}$ dependencies on $V_{\mathrm{j}}$ (Fig. 6d, top panel). Moreover, transjunctional asymmetry in $\left[\mathrm{Mg}^{2+}\right]_{\mathrm{i}}$ induced asymmetric steady-state and instantaneous $g_{j}-V_{j}$ dependencies (Fig. 6e, top panel). The effects of symmetric and asymmetric $\left[\mathrm{Mg}^{2+}\right]_{\mathrm{i}}$ on steady-state and instantaneous $g_{\mathrm{j}}-V_{\mathrm{j}}$ dependencies were still present, albeit reduced, in GJs formed by Cx36*D47G (Fig. 6c-e, middle panels, \& Fig. 6f), but absent for $g_{\mathrm{j}, \text { inst }}-V_{\mathrm{j}}$ dependence in GJs formed by $\mathrm{CH} 3$ (Fig. 6c-e, bottom panels). In addition, we found that the effects of $\left[\mathrm{Mg}^{2+}\right]_{i}$ were eliminated in $\mathrm{CH} 1$ only for $g_{\mathrm{j}, \text { inst }}-V_{\mathrm{j}}$ but not for $g_{\mathrm{j}, \mathrm{ss}}-V_{\mathrm{j}}$ dependencies (Supplementary Fig. 7), suggesting that residues in NT or M1 of Cx36 are necessary for the peculiar hyperbola-like $g_{\text {j,inst }}-V_{j}$ rectification. Altogether, these results suggest that $\left[\mathrm{Mg}^{2+}\right]_{\mathrm{i}}$ affects Cx36 GJ channels by: (1) gating through its binding in E1 and/or stabilizing a closed conformation of the channel; and (2) rectification of $I_{j, \text { inst }}$ depending on $V_{j}$ (see Discussion).

$\mathrm{Mg}^{2+}$-sensitive heterotypic GJs show asymmetric $\boldsymbol{g}_{\mathbf{j}}-V_{\mathrm{j}}$ relation. Heterotypic GJs formed by Cxs with highly different properties, such as $\mathrm{Cx} 36$ and $\mathrm{Cx} 43$, present a valuable tool for a highresolution analysis of the individual aHC properties. Our studies revealed that $\mathrm{Cx} 36$ does not form either JPs or functional coupling with $\mathrm{Cx} 43$, consistent with reports that neurons and astrocytes do not form $\mathrm{Cx} 36 / \mathrm{Cx} 43$ heterotypic GJs ${ }^{51}$. We found that $\mathrm{Cx} 36$ or $\mathrm{Cx} 43$ were able to form functional heterotypic channels with $\mathrm{CH}$ that contain $\mathrm{E} 2$ of $\mathrm{Cx} 36$ or $\mathrm{Cx} 43$, respectively (Fig. 7). Thus, E2 determines incompatibility between Cx36 and Cx43. For heterotypic pairings, we used $\mathrm{Cx} 36$ and $\mathrm{Cx} 43$ tagged with CFP, while all $\mathrm{CH}$ were tagged with EGFP. This allowed us to detect junctional plaques with heterotypic GJs visible in two colours $^{28}$. In $\mathrm{Cx} 43 / \mathrm{CH} 3$ heterotypic GJs, both aHCs have a similar unitary conductance $\left(\gamma_{\text {open,H}}\right)$, but differential sensitivity to $\left[\mathrm{Mg}^{2+}\right]_{\mathrm{i}}$ (Figs 3 and 4 ). Thus, this heterotypic configuration allows the study of $\mathrm{Mg}^{2+}$-sensitivity in $\mathrm{CH} 3 \mathrm{aHCs}$, and any detected asymmetry can be attributed to the difference in $\mathrm{Mg}^{2+}$ sensitivity of aHCs but not $\gamma_{\text {open,H}}$. Indeed, heterotypic $\mathrm{Cx} 43 / \mathrm{CH} 3$ GJs show marked asymmetric $g_{\mathrm{j}, \mathrm{ss}}-V_{\mathrm{j}}$ dependence under symmetric high $\left[\mathrm{Mg}^{2+}\right]_{\mathrm{i}}$ (Fig. 8a). At $\left[\mathrm{Mg}^{2+}\right]_{\mathrm{p}}=5 \mathrm{mM}$, positive $V_{\mathrm{j}}$ ramps applied on the $\mathrm{Cx} 43$ side induced strong gating of the $\mathrm{CH} 3 \mathrm{aHC}$, suggesting that $\mathrm{CH} 3$ aHCs have a negative gating polarity, as has been proposed for $\mathrm{Cx} 43$ (ref. 52). However, $V_{\mathrm{j}}$-dependent gating of $\mathrm{CH} 3$ aHC at negative $V_{\mathrm{j}} \mathrm{s}$ almost disappears under symmetric low $\left[\mathrm{Mg}^{2+}\right]_{\mathrm{i}}$ (Fig. 8b). At the single-channel level, heterotypic $\mathrm{Cx} 43 / \mathrm{CH} 3 \mathrm{GJs}$ showed asymmetric gating behaviour (Fig. 8c). Negative $V_{\mathrm{j}}$ steps applied on the $\mathrm{Cx} 43$ side induced fast flickering of channels, while positive $V_{\mathrm{j}}$ steps induced channel closing (Fig. 8c). Moreover, the asymmetric gating behaviour of homotypic $\mathrm{CH} 3 \mathrm{GJ}$ channels under asymmetric $\left[\mathrm{Mg}^{2+}\right]_{\mathrm{i}}$ (Fig. 5c) can be replicated in heterotypic $\mathrm{Cx} 43 / \mathrm{CH} 3$ channels under symmetric $\left[\mathrm{Mg}^{2+}\right]_{\mathrm{i}}$ (Fig. 8d). As expected from $\gamma_{\text {open }}$ s of $\mathrm{Cx} 43$ and $\mathrm{CH} 3$ homotypic GJs, the $\gamma_{\text {open }}$ of heterotypic Cx43/CH3 GJs is $\sim 110 \mathrm{pS}$, and does not change under high or low $\left[\mathrm{Mg}^{2+}\right]_{\mathrm{i}}$. Thus, the macroscopic 
asymmetric $g_{\mathrm{j}, \mathrm{ss}}-V_{\mathrm{j}}$ dependence shown in Fig. 8a can be explained by a $\mathrm{Mg}^{2}{ }^{+}$-dependent modulation of gating mechanisms, in which negative potentials induce the transition of gates to a closed state, while positive potentials tend to reopen the gates. At low $\left[\mathrm{Mg}^{2+}\right]_{\mathrm{i}}$, most of the $V_{\mathrm{j}}$-dependent gating is lost (Fig. $8 \mathrm{~b}$ ), suggesting that $\mathrm{Mg}^{2+}$ is necessary for $V_{\mathrm{j}}$-sensitive gating. Furthermore, we studied $g_{\mathrm{j}, \mathrm{ss}}-V_{\mathrm{j}}$ dependence of $\mathrm{Cx} 43 / \mathrm{CH} 3 \mathrm{GJ} s$ under asymmetric $\left[\mathrm{Mg}^{2+}\right]_{\mathrm{i}}$ (Fig. 8e,f). These experiments revealed that the direction of the $\mathrm{Mg}^{2+}$ gradient is important; the $g_{\mathrm{j}, \mathrm{ss}}-V_{\mathrm{j}}$ asymmetry is strengthened when the $\mathrm{Cx} 43$ side has higher $\left[\mathrm{Mg}^{2+}\right]_{\mathrm{i}}$ (Fig. 8e) or reduced when the $\mathrm{Cx} 43$ side has lower $\left[\mathrm{Mg}^{2+}\right]_{\mathrm{i}}$ (Fig. 8f). These results strongly support the hypothesis that the site of $\mathrm{Mg}^{2+}$ interaction in $\mathrm{CH} 3 \mathrm{aHC}$ is

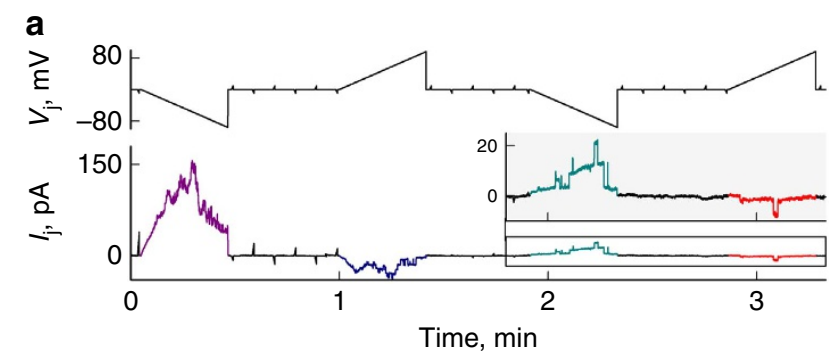

b

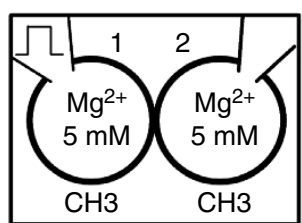

c

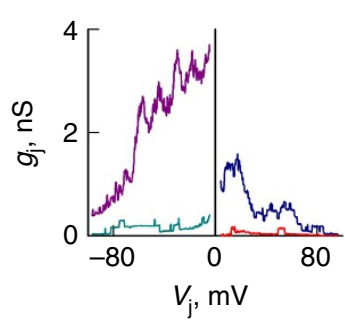

d

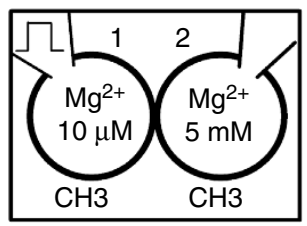

e

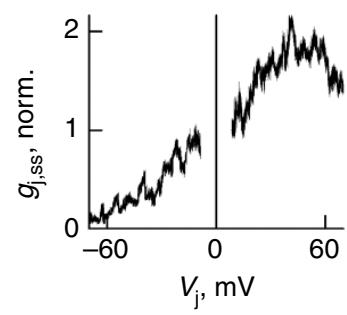

f

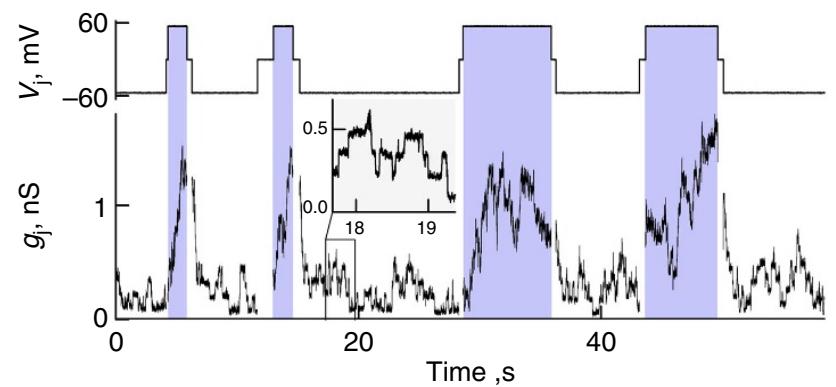

g

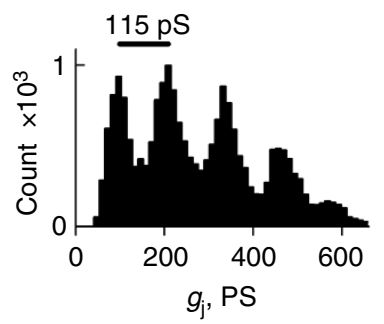

$\mathbf{h}$

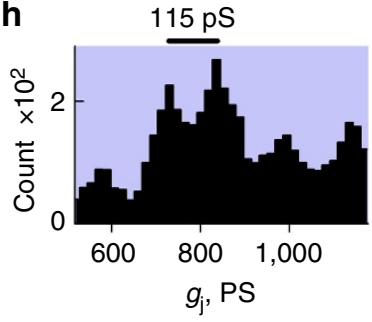

located within the pore, and that high $\left[\mathrm{Mg}^{2+}\right]$ inside the pore increases $V_{\mathrm{j}}$-sensitive gating.

We studied $g_{\mathrm{j}, \mathrm{ss}}-V_{\mathrm{j}}$ and $g_{\mathrm{j} \text {,inst }}-V_{\mathrm{j}}$ dependencies and sensitivity to $\left[\mathrm{Mg}^{2+}\right]_{i}$ of $\mathrm{Cx} 36$ aHC in Cx36/CH4 heterotypic GJs. This heterotypic configuration allows for a higher resolution analysis of $\mathrm{Mg}^{2}+$ sensitivity and of $V_{\mathrm{j}}$ gating of Cx36 aHCs; in Cx36/CH4 GJs, almost all $V_{\mathrm{j}}$ drops across the Cx36 aHCs due to a $\sim 15$-fold lower $\gamma_{\text {open, } \mathrm{H}}$ than in $\mathrm{CH} 4$ (ref. 53), making $\mathrm{CH} 4$ aHC virtually insensitive to $V_{\mathrm{j}}$. We found that under high symmetric $\left[\mathrm{Mg}^{2+}\right]_{\mathrm{p}}$ $(5 \mathrm{mM}), g_{\text {j,inst }}$ (normalized to $g_{\mathrm{j}}$ value at zero $V_{\mathrm{j}}$ ) of heterotypic Cx36/CH4 GJs increased for both polarities of $V_{j}$ (Fig. 9a, bottom), while $g_{\mathrm{j}, \mathrm{ss}}-V_{\mathrm{j}}$ showed a marked asymmetric dependence (Fig. 9a, top). Interestingly, $g_{\text {,inst }}-V_{\mathrm{j}}$ dependence of heterotypic Cx36/CH4 GJs becomes less symmetric at low $\left[\mathrm{Mg}^{2+}\right]_{\mathrm{p}}$ (Fig. 9 b, bottom), in which $g_{\text {,inst }}$ increased only at relative negativity on the $\mathrm{Cx} 36$ side. The asymmetric $g_{\mathrm{j}, \mathrm{ss}}-V_{\mathrm{j}}$ dependence almost disappears under low $\left[\mathrm{Mg}^{2+}\right]_{\mathrm{p}}(0.01 \mathrm{mM}$, Fig. $9 \mathrm{~b}$, top $)$ due to a reduction in $V_{\mathrm{j}}$ sensitivity, indicating that most of the asymmetry is due to the $\mathrm{Mg}^{2+}$ sensitivity of $\mathrm{Cx} 36$ aHC. To study the mechanism of $I_{\mathrm{j}, \text { inst }}-V_{j}$ rectification of the Cx36 aHC in more detail, we simulated $g_{\text {,inst }}-V_{\mathrm{j}}$ dependence curves that fit our experimental data using a stochastic four state model (S4SM) of GJ channels ${ }^{54} \cdot g_{\text {j,inst }}-V_{\mathrm{j}}$ relationships of the Cx36 homotypic and $\mathrm{Cx} 36 / \mathrm{CH} 4$ heterotypic GJs were simulated using a hyperbolic equation describing the $\mathrm{Cx} 36$ aHC conductance: $\gamma_{\text {open, } \mathrm{H}}=\gamma_{\text {open, }, 0}{ }^{*}\left(\mathrm{e}^{\left(V_{H} / r_{H}\right)}+\mathrm{e}^{\left(-V_{H} / r_{M g}\right)}\right) / 2$, where $\gamma_{\text {open, }, 0}$ is $\gamma_{\mathrm{open}, \mathrm{H}}$ at $V_{\mathrm{H}}=0, V_{\mathrm{H}}$ is voltage across aHC, $r_{\mathrm{H}}$ and $r_{\mathrm{Mg}}$ are $\mathrm{Mg}^{2+}$-independent and $\mathrm{Mg}^{2+}$-dependent rectification coefficients of aHC, respectively. The $\mathrm{CH} 4 \mathrm{aHC}$ conductance was described using a single exponential equation: $\gamma_{\text {open, } \mathrm{H}}=\gamma_{\mathrm{open}, \mathrm{H}, 0}{ }^{*} \mathrm{e}^{\left(V_{H} / r_{H}\right)}$. The simulated $g_{\mathrm{j} \text {,inst }}-V_{\mathrm{j}}$ curves for $\mathrm{Cx} 36$ (pink) and $\mathrm{CH} 4$ (purple) aHCs produced curves with good fit (grey) for steady state and instantaneous $g_{\mathrm{j}}-V_{\mathrm{j}}$ dependence of experimental data from heterotypic $\mathrm{Cx} 36 / \mathrm{CH} 4 \mathrm{GJs}$ at low and high symmetric $\left[\mathrm{Mg}^{2+}\right]_{i}$ (Fig. 9a,b). The same hyperbolic equation describing $\gamma_{\text {open,H }}$ of $\mathrm{Cx} 36$ and similar rectification values used in simulation of heterotypic $\mathrm{Cx} 36 / \mathrm{CH} 4$ GJs were also used to simulate experimental data for homotypic Cx36 GJs at high and low $\left[\mathrm{Mg}^{2+}\right]_{\mathrm{i}}$ (Fig. 9c,d). All values of rectification and gating parameters are presented in Supplementary Table 1.

\section{Discussion}

Electrical synapses are known to function throughout the mammalian CNS, and Cx36 expression is necessary to produce

Figure $\mathbf{5} \mid \mathbf{M g}^{2}+$ effect on $\boldsymbol{V}_{\mathbf{j}}$ gating and single-channel conductance of homotypic GJs formed of CH3. (a) Changes of $l_{j}$ (bottom trace) of $\mathrm{CH} 3$ GJs in response to repeated $30 \mathrm{~s}$ long $V_{\mathrm{j}}$ ramps from 0 to $-90 \mathrm{mV}$ and from 0 to $+90 \mathrm{mV}$ with intermediate small amplitude ramps $(-10 \mathrm{mV}$; top trace) using symmetric $\left[\mathrm{Mg}^{2+}\right]_{\mathrm{p}}=5 \mathrm{mM}$. (b,d) Diagrams illustrating $\left[\mathrm{Mg}^{2+}\right]_{\mathrm{p}}$ in cell-1 and cell-2 and the stimulation site of the $V_{\mathrm{j}}$ protocol for experiments shown in a and $\mathbf{c}(\mathbf{b})$ or $\mathbf{e}(\mathbf{d})$. (c) $g_{\mathrm{j}}-V_{\mathrm{j}}$ relations obtained from experiment shown in a. Colours match the $l_{\mathrm{j}}$ data shown in $\mathbf{a}$. (e) Asymmetric $g_{\mathrm{j}, \mathrm{ss}}-V_{\mathrm{j}}$ dependence (normalized to $g_{\mathrm{j}}$ value at $V_{\mathrm{j}}$ zero) was measured by applying $V_{j}$ ramps from 0 to -70 and from 0 to $+70 \mathrm{mV}$ (30 $\mathrm{s}$ in duration) under transjunctional $\mathrm{Mg}^{2+}$ asymmetry shown in $\mathbf{d}$. Negative potentials applied on the side with low $\left[\mathrm{Mg}^{2+}\right]_{\mathrm{i}}$ decreased $g_{\mathrm{j}}$ presumably by increasing $\mathrm{Mg}^{2+}$ occupancy of the pore through ionophoresis $(n=4)$. (f) $g_{\mathrm{j}}$ trace (bottom) showing unitary gating events of the homotypic $\mathrm{CH} 3 \mathrm{GJ}$ channel obtained during $V_{\mathrm{j}}$ steps of $\pm 55 \mathrm{mV}$ (top trace) applied in cell-1 (as illustrated in $\mathbf{d}$ ). Negative $V_{\mathrm{j}} \mathrm{s}$ facilitated closing transitions, whereas positive $V_{\mathrm{j}} \mathrm{s}$ facilitated opening transitions. (g-h) Count histograms for all $g_{\mathrm{j}}$ data obtained at negative ( $\mathbf{g}$ ) or positive (h) $V_{j} s$ shown in (f). Both histograms show peaks corresponding to the single-channel conductance of $\sim 115 \mathrm{pS}$. 


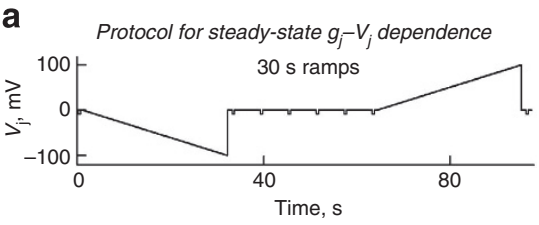

C
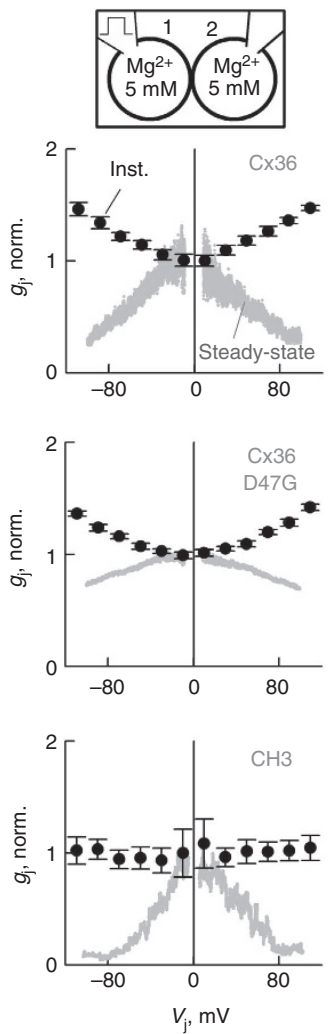

d
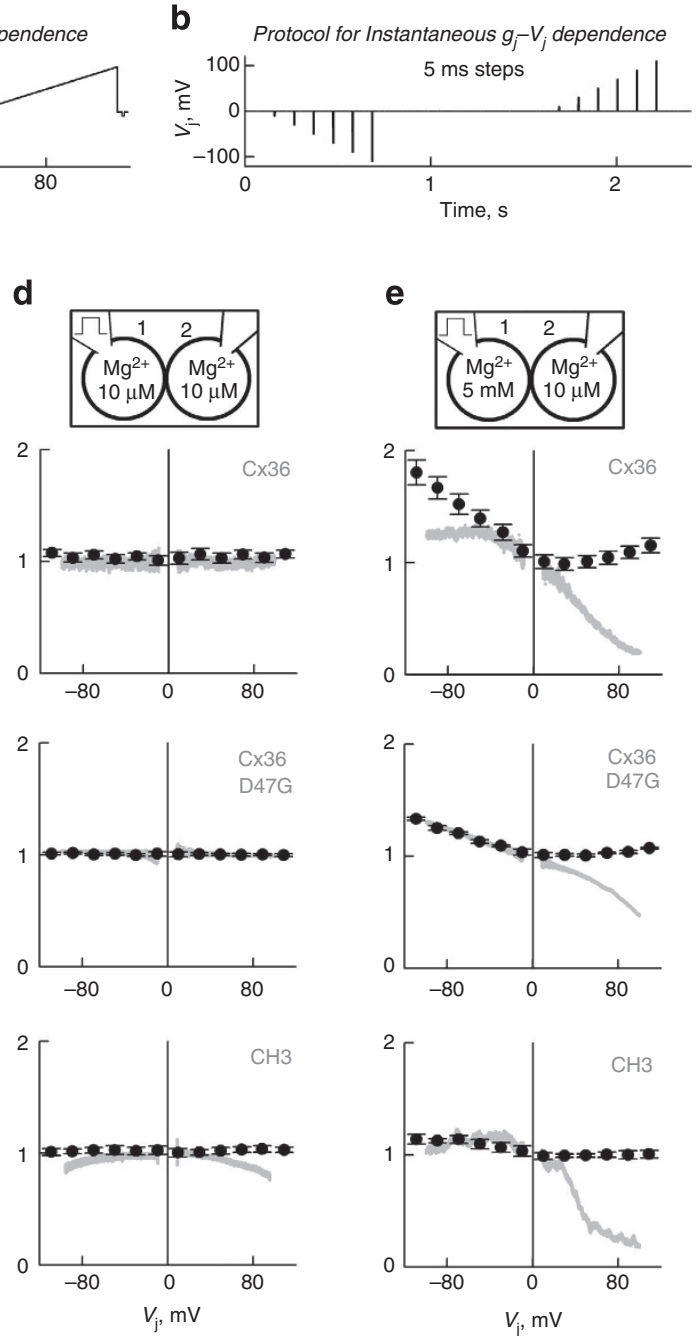

e
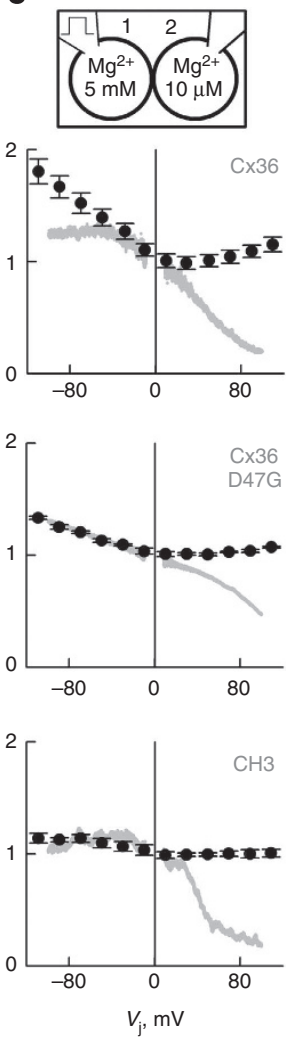

f

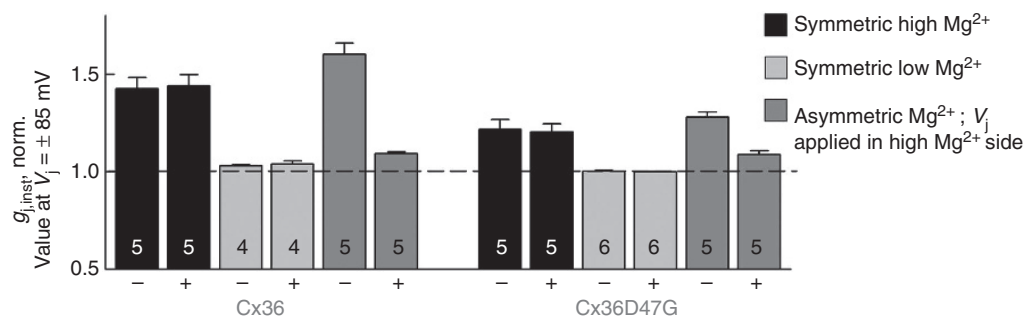

Figure 6 | GJs formed by $\mathbf{C x 3 6}$ show $\mathbf{M g}^{2+}$-dependent rectification of both steady-state and instantaneous conductance-voltage relationships. $(\mathbf{a}, \mathbf{b}) V_{\mathrm{j}}$ protocols used to obtain steady-state (a) and instantaneous $(\mathbf{b}) g_{\mathrm{j}}-V_{\mathrm{j}}$ relationships. (c-e) Steady-state (grey) and instantaneous $\left(\right.$ black) $g_{\mathrm{j}}-V_{\mathrm{j}}$ relationships (normalized to $g_{\mathrm{j}}$ value at $V_{\mathrm{j}}$ zero) were measured $\sim 30 \mathrm{~min}$ after opening of patches under symmetric high (c), low (d), and asymmetric $\mathrm{Mg}^{2+}$ conditions (e) in homotypic GJs formed of Cx36 (top row), Cx36*D47G (middle row) and CH3 (bottom row). Each data point for instantaneous $g_{\mathrm{j}}-V_{\mathrm{j}}$ relationships was obtained by averaging data from $\sim 10$ consecutive $V_{\mathrm{j}}$ protocols shown in $\mathbf{b}$, and error bars correspond to s.e.m. Top diagrams in each column show $\left[\mathrm{Mg}^{2+}\right]_{\mathrm{p}}$ and stimulation site. (f) Mean $g_{\mathrm{j}, \text { inst }}$ values measured at $V_{\mathrm{j}} \mathrm{s}$ equal to -85 and $+85 \mathrm{mV}$ (normalized to $g_{\mathrm{j}, \text { inst }}$ value at $V_{\mathrm{j}}$ zero) at symmetric high (black) and low (light grey) $\left[\mathrm{Mg}^{2+}\right]_{\mathrm{p}}$, and asymmetric $\mathrm{Mg}^{2+}$ conditions (dark grey) for GJs formed of $\mathrm{C} \times 36$ (left) and Cx36*D47G (right). Total numbers of cell pairs are indicated within columns, and error bars correspond to s.e.m.

robust neuronal coupling in many brain areas ${ }^{35}$. We recently showed $\mathrm{Mg}^{2+}$-dependent modulation of signal transfer at electrical synapses between excitatory MesV neurons in the midbrain and that this $\left[\mathrm{Mg}^{2+}\right]_{i}$ effect was similar to that observed in heterologous expression systems ${ }^{43}$.

Here, we demonstrated that electrical synapses formed by $\mathrm{Cx} 36$ GJs between GABAergic interneurons in the TRN also show $\mathrm{Mg}^{2+}$-dependent synaptic plasticity, and that the ratio between the total intracellular ATP and $\mathrm{Mg}^{2+}$ contributes to regulation of electrical coupling (Fig. 1). Although the magnitude of changes in $g_{\mathrm{j}}$ between TRN (Fig. 1) and MesV ${ }^{43}$ neurons were significant ( $\sim 30-40 \%)$, they were smaller than those observed in RIN cells expressing Cx36. This distinction may be explained by differences in the initial $\left[\mathrm{Mg}^{2+}\right]_{\mathrm{i}}$ and other divalent cations as well as the concentration of ATP and phosphocreatine, that exert a $\mathrm{Mg}^{2+}$ buffering capacity, and the location of JPs with respect to patch pipette attachment at the soma. Despite these differences, the magnitude of $g_{\mathfrak{j}}$ changes is comparable to that 


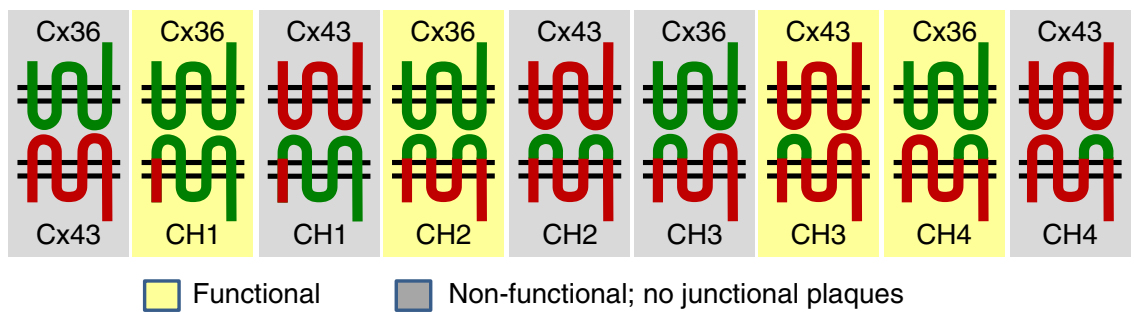

Figure 7 | Compatibility between Cx36 and Cx43 GJ channels with functional CH. Among all examined heterotypic combinations between wild-type $\mathrm{C} \times 36$ (green) or $\mathrm{C} \times 43$ (red) with $\mathrm{CH} 1, \mathrm{CH} 2, \mathrm{CH} 3$ or $\mathrm{CH} 4$, only those shown in yellow background formed junctional plaques and exhibit electrical cell-cell coupling, while those shown in grey background did not form junctional plaques or exhibit electrical cell-cell coupling.

of previous reports on long-term depression or potentiation of neuronal coupling ${ }^{40,42}$. Taken together, these results support the hypothesis that $\mathrm{Mg}^{2+}$-dependent synaptic plasticity of Cx36-containing electrical synapses is neuronal-type independent and is a common mechanism that affects the strength of neuronal electrical coupling in the CNS.

We recently suggested that $\mathrm{Mg}^{2+}$ exerts its effects on $g_{j}$ of Cx36 GJs via interaction with a domain in the channel lumen ${ }^{43}$. This interaction may affect $V_{\mathrm{j}}$-sensitive gates by modulating their sensitivity to voltage and stabilizing a closed state conformation ${ }^{43}$. Previously, we showed that sensitivity to high $\left[\mathrm{Mg}^{2+}\right]_{\mathrm{i}}$ is similar in wild-type $\mathrm{Cx} 36$ and $\mathrm{Cx} 43$, and tagged with fluorescent proteins ${ }^{43}$. Here, using colour variants of GFP tagged to $\mathrm{Cx} 36 /$ $\mathrm{Cx} 43 \mathrm{CH}$ and mutants, we demonstrate that $\mathrm{E} 1$ of $\mathrm{Cx} 36$ contains a $\mathrm{Mg}^{2+}$-sensitive domain and that it can be transferred to $\mathrm{Cx} 43$ (Fig. 3). In addition, single amino acid substitutions targeted to $\mathrm{E} 1$ of $\mathrm{C} \times 36$ and $\mathrm{C} \times 43$ revealed that residues in $\mathrm{E} 1$ are indeed responsible for the sensitivity to $\mathrm{Mg}^{2+}$ and that particularly D47 is critical for high $\mathrm{Mg}^{2}+$ sensitivity in Cx36 GJs (Fig. 3). Interestingly, the G46D mutation in Cx43 (corresponding location of D47 in Cx36) was sufficient to significantly increase sensitivity to $\mathrm{Mg}^{2+}$ in $\mathrm{Cx} 43$ (Fig. 3). Furthermore, as predicted from the crystal structure of $\mathrm{Cx} 26$ (ref. 55), the side chains of the residue D47 in GJs formed by Cx36 face the pore, form a negatively charged hexameric ring and contribute significantly to the negative surface potential of the pore (Fig. $10 \mathrm{a}-\mathrm{c}$ ), supporting the view that $\mathrm{Mg}^{2}+$ interacts with a pore-lining domain located in E1 and that residue D47 provides strong electro negative surface potential, which may increase $\mathrm{Mg}^{2}+$ occupancy. It is noteworthy that recent quantum chemistry studies in $\mathrm{Cx} 26$ structure have proposed that $\mathrm{Ca}^{2+}$ may directly interact with E47 (E49 in Cx36) to induce closure of the channel by a gating mechanism ${ }^{56}$. Other intracellular cations, such as spermine, have been shown to affect $V_{\mathrm{j}}$-dependent gating mechanisms by interacting with charged residues located in the $\mathrm{N}$ terminus ${ }^{57}$. In addition, spermine can influence the Mg-ATP binding affinity ${ }^{2}$, and therefore modulate its action on $g_{j}$ and gating.

Single-channel analysis of $\mathrm{Cx} 43$-based $\mathrm{CH}$ and mutants $(\mathrm{CH} 2$, $\mathrm{CH} 3, \mathrm{CH} 4$ and $\left.\mathrm{Cx} 43^{*} \mathrm{G} 46 \mathrm{D}\right)$ showed that $\gamma_{\text {open }}$ is not affected by $\left[\mathrm{Mg}^{2+}\right]_{\mathrm{i}}$ (Fig. 4), and a long-lived residual state is absent, indicating that the fast gating mechanism is inhibited most likely due to $\mathrm{C}$ terminus tagging by fluorescent proteins ${ }^{58}$. The latter can reduce $g_{j, s s}$ dependence on $V_{j}$ in $\mathrm{Cx} 43 / \mathrm{CH} 3$ heterotypic GJs (Fig. 8), but should not influence $g_{\mathrm{j}, \mathrm{ss}}-V_{\mathrm{j}}$ dependence of Cx36/CH4 GJs (Fig. 9) due to a significant difference in $\gamma_{\text {open,H }}$ of $\mathrm{Cx} 36$ and $\mathrm{CH} 4$ aHCs, making $\mathrm{CH} 4$ aHC unlikely to be gated by $\mathrm{V}_{\mathrm{j}}$. In addition, $\gamma_{\text {open }}$ and $V_{\mathrm{j}}$-sensitive gating records under transjunctional asymmetry in $\left[\mathrm{Mg}^{2+}\right]_{i}$ allowed us to conclude that changes in $\left[\mathrm{Mg}^{2+}\right]$ inside the pore are necessary for the observed asymmetry in the $g_{\mathrm{j}, \mathrm{ss}}-V_{\mathrm{j}}$ relationship of $\mathrm{CH} 3 \mathrm{GJs}$ (Figs $5 \mathrm{~d}-\mathrm{f}$ and $8 \mathrm{e}, \mathrm{f}$ ).
Cx36 is not compatible to dock with $\mathrm{Cx} 43$, but is compatible with $\mathrm{CH} 2$ and $\mathrm{CH} 4$. $\mathrm{Cx} 43$ is compatible with $\mathrm{CH} 1$ and $\mathrm{CH} 3$ but not with $\mathrm{CH} 2$ and $\mathrm{CH} 4$ (Fig. 7). These data suggest that E2 is an important structural determinant for the incompatibility between $\mathrm{Cx} 36$ and $\mathrm{Cx} 43$, consistent with reports showing the key role E2 plays in determining compatibility between different $\mathrm{Cxs}^{59,60}$. $\mathrm{Cx} 43 / \mathrm{CH} 3$ heterotypic GJs showed a marked asymmetry in the $g_{\mathfrak{j}}-V_{\mathrm{j}}$ relationship, and this asymmetry was dependent on $\left[\mathrm{Mg}^{2+}\right]_{\mathrm{i}}$ (Fig. 8a,b). CH3 GJs exhibited similar sensitivity to $\mathrm{Mg}^{2}+$ compared with that of $\mathrm{Cx} 36$ (Fig. 3), while its $\gamma_{\text {open }}$ is $>15$-fold higher than that of $\mathrm{Cx} 36$. Macroscopic and singlechannel recordings of $\mathrm{Cx} 43 / \mathrm{CH} 3$ GJs (Fig. 8a,d) under high $\left[\mathrm{Mg}^{2+}\right]_{\mathrm{i}}$ show significant $V_{\mathrm{j}}$ gating asymmetry with pronounced sensitivity to $V_{j}$ at relative negativity on the $\mathrm{CH} 3$ side. The dependence of $V_{\mathrm{j}}$ gating asymmetry on the $\mathrm{Mg}^{2+}$ gradient in $\mathrm{Cx} 43 / \mathrm{CH} 3$ heterotypic GJs (Fig. 8e,f) demonstrates that asymmetric gating is determined not only by $\left[\mathrm{Mg}^{2+}\right]_{\mathrm{i}}$ concentration inside the pore, but also by its influence on $V_{\mathrm{j}}$ sensitivity. When $\left[\mathrm{Mg}^{2+}\right]_{\mathrm{i}}$ is higher on the Cx43 side, the $g_{\mathrm{j}, \mathrm{ss}}-V_{\mathrm{j}}$ asymmetry is enhanced compared to that under high symmetric $\left[\mathrm{Mg}^{2+}\right]_{\mathrm{i}}$. These effects are presumably due to increased $V_{\mathrm{j}}$ gating and $\mathrm{Mg}^{2}+$ occupancy during positive $V_{\mathrm{j}}$ s applied on the $\mathrm{Cx} 43$ side, and decreased $V_{\mathrm{j}}$ gating and $\mathrm{Mg}^{2}+$ occupancy during negative $V_{\mathrm{j}}$ s applied on the $\mathrm{Cx} 43$ side (Fig. 8e). Conversely, when $\left[\mathrm{Mg}^{2+}\right]_{\mathrm{i}}$ is lower on the $\mathrm{Cx} 43$ side, the $g_{\mathrm{j}}-V_{\mathrm{j}}$ asymmetry is reduced and opposite compared with the one at high symmetric $\left[\mathrm{Mg}^{2+}\right]_{\mathrm{i}}$ (Fig. 8f). Consistent with our data, a three-state model of $\mathrm{Mg}^{2+}$-dependent gating of $\mathrm{Cx} 37 \mathrm{HCs}$, also suggests the stabilization of a closed state by $\mathrm{Mg}^{2}+$ binding ${ }^{61}$.

We found a unique $g_{\text {j,inst }}-V_{\mathrm{j}}$ relationship dependence on $\left[\mathrm{Mg}^{2+}\right]_{\mathrm{i}}$ of $\mathrm{Cx} 36 \mathrm{GJ}$ channels. Reported and preliminary data show that all examined Cxs with the exception of Cx36 demonstrate no or minimal decay of $g_{\mathrm{j} \text {,inst }}$ dependence on $V_{\mathrm{j}}$ for both $V_{\mathrm{j}}$ polarities ${ }^{52}$. The symmetric increase in $g_{\mathrm{j}, \text { inst }}$ at high $V_{\mathrm{j}} \mathrm{s}$ for Cx36 was previously reported in the oocyte expression system at normal/resting $\left[\mathrm{Mg}^{2+}\right]_{\mathrm{i}}^{62}$. Here, we show that $g_{\text {j,inst }} \mathrm{s}$ at high $\left[\mathrm{Mg}^{2+}\right]_{\mathrm{i}}$ increases $\sim 1.4$ fold at $V_{\mathrm{j}}= \pm 100 \mathrm{mV}$, and that this increase disappears under low $\left[\mathrm{Mg}^{2+}\right]_{\mathrm{i}}$ (Fig. 6c,d). All our attempts to replicate the observed $g_{\mathrm{j} \text {,inst }}-V_{\mathrm{j}}$ dependence at high $\left[\mathrm{Mg}^{2+}\right]_{\mathrm{i}}$ using a one-dimensional Poisson-Nernst-Plank model $^{63}$ were unsuccessful. Studies of heterotypic $\mathrm{CH} 4 / \mathrm{Cx} 36$ GJs show that $g_{\text {j,inst }}$ increased for both polarities of $V_{\mathrm{j}}$ at high $\left[\mathrm{Mg}^{2+}\right]_{\mathrm{i}}$ (Fig. 9a) and only at relative negativity of $V_{\mathrm{j}}$ at low $\left[\mathrm{Mg}^{2+}\right]_{\mathrm{i}}$ on the Cx36 side (Fig. 9b). Thus, the $g_{\mathrm{j}, \text { inst }}-V_{\mathrm{j}}$ relationship of $\mathrm{Cx} 36$ aHC transforms from hyperbola-like to exponential-like when $\left[\mathrm{Mg}^{2+}\right]_{\mathrm{p}}$ decreases from 5 to $0.01 \mathrm{mM}$ (Fig. 9a,b). An approximately 15-fold difference in $\gamma_{\text {open, } \mathrm{H}}$ between $\mathrm{Cx} 36$ and $\mathrm{CH} 4$ aHCs allows us to assume that measured $g_{\mathrm{j} \text {,inst }}-V_{\mathrm{j}}$ rectification in $\mathrm{Cx} 36 / \mathrm{CH} 4 \mathrm{GJs}$ can be attributed solely to the $\mathrm{Cx} 36$ aHC. These data suggest that $g_{\text {j,inst }}-V_{\mathrm{j}}$ rectification of $\mathrm{Cx} 36$ aHC contains two exponential-like components in opposite orientation with respect to $V_{\mathrm{j}}$ polarity, 
a

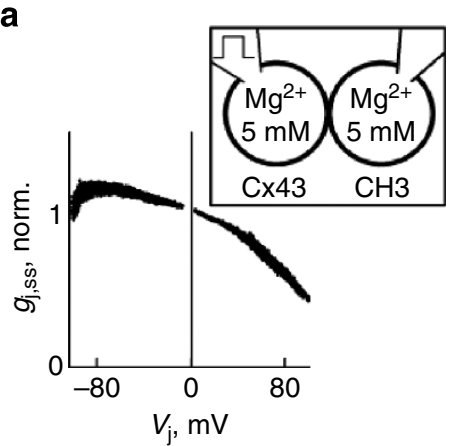

b

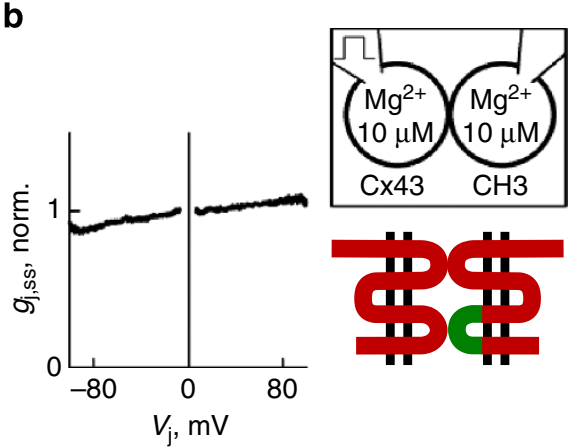

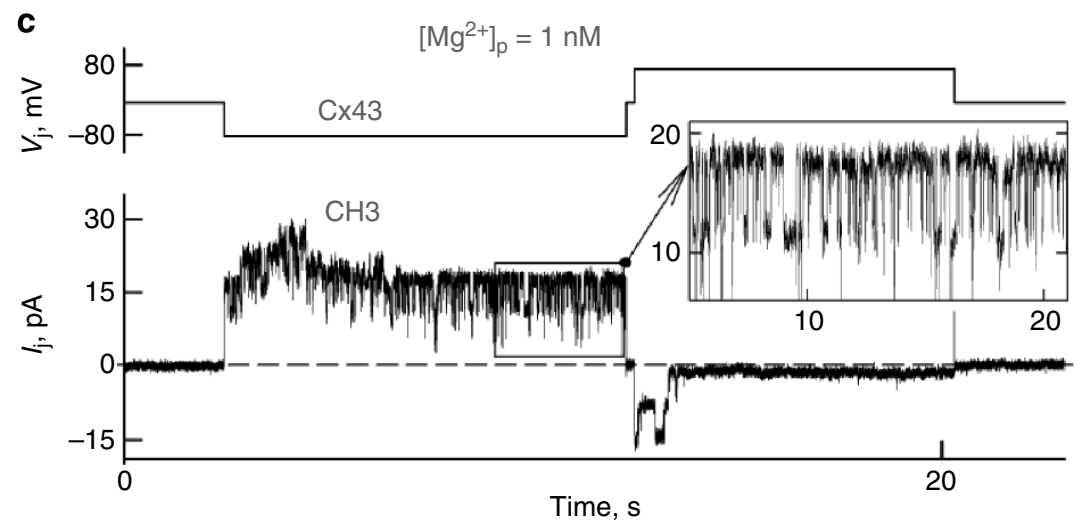

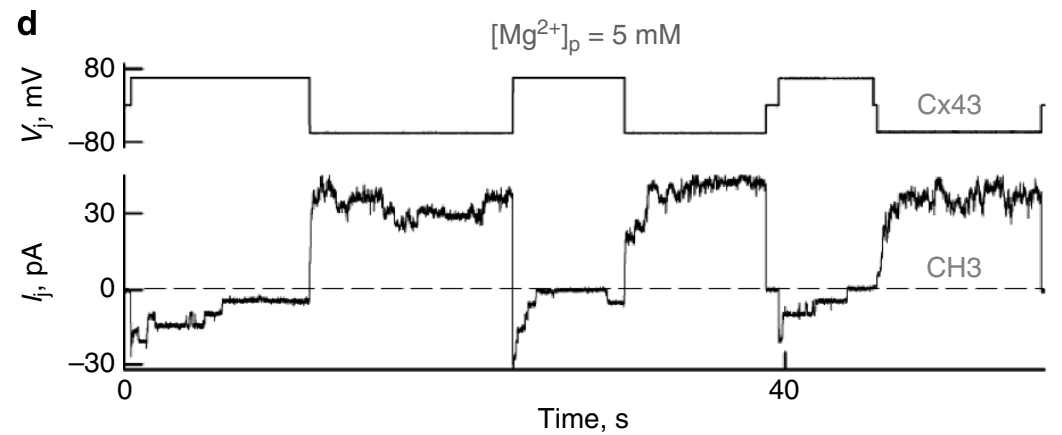

e

$\mathbf{f}$
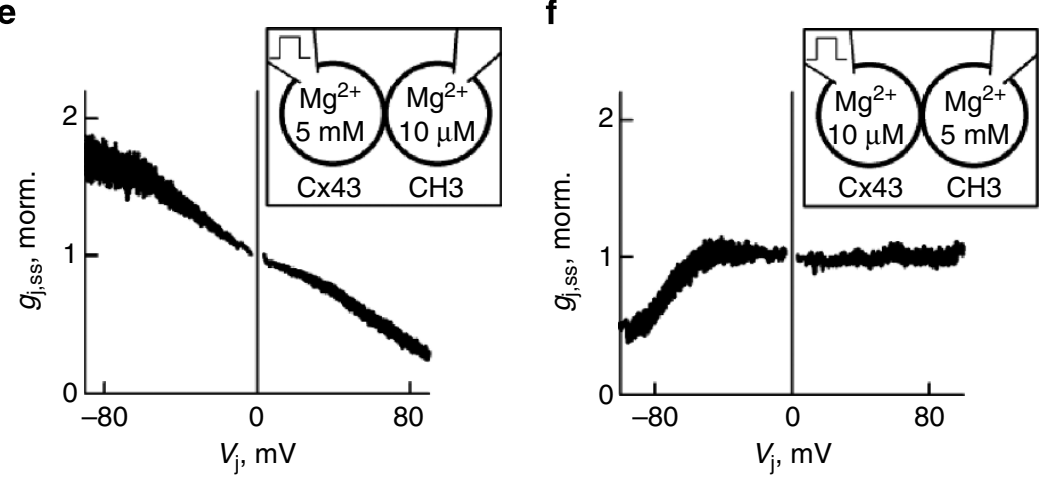

Figure $8 \mid \mathbf{M g}^{2+}$-dependent asymmetry in steady-state $\boldsymbol{g}_{\mathrm{j}}-\boldsymbol{V}_{\mathbf{j}}$ relationship and single channel conductance in $\mathbf{C x 4 3 / C H 3 ~ h e t e r o t y p i c ~} \mathbf{G J s}$.

$(\mathbf{a}, \mathbf{b})$ Asymmetric $g_{\mathrm{iss}}-V_{\mathrm{j}}$ relationships (normalized to $g_{\mathrm{j}, \mathrm{ss}}$ value at $V_{\mathrm{j}}=0$, and obtained using the same $V_{j}$ protocol shown in Fig. 6a) with pipette solutions containing symmetric high (a) or low (b) $\left[\mathrm{Mg}^{2+}\right]_{\mathrm{p}}$ in heterotypic $\mathrm{Cx} 43 / \mathrm{CH} 3 \mathrm{GJs}(n=5)$. Top diagram in each plot shows $\left[\mathrm{Mg}^{2+}\right]_{\mathrm{p}}$ used in cell-1 and cell-2, stimulation sites and expressed Cxs. (c) $l_{j}$ records of single-channel events at symmetric $\left[\mathrm{Mg}^{2+}\right]_{\mathrm{p}}$ obtained during $V_{\mathrm{j}}$ steps of $\pm 85 \mathrm{mV}$ (top trace) applied in cell-1 expressing $\mathrm{C} \times 43$. (d) $l_{\mathrm{j}}$ records (bottom trace) under symmetric high $\left[\mathrm{Mg}^{2+}\right]_{\mathrm{p}}$ showing unitary gating events of $\mathrm{C} \times 43 / \mathrm{CH} 3 \mathrm{GJ}$ channel obtained during $V_{\mathrm{j}}$ steps of $\pm 60 \mathrm{mV}$ (top trace) applied in cell-1 expressing $C \times 43$. Positive $V_{\mathrm{j}} \mathrm{s}$ facilitated closing transitions, while negative $V_{\mathrm{j}} \mathrm{s}$ facilitated opening transitions. (e,f) Asymmetric $g_{\mathrm{jss}}-V_{\mathrm{j}}$ relationships (normalized to $g_{\mathrm{j}, \mathrm{ss}}$ value at $V_{\mathrm{j}}=0$ ) obtained under asymmetric $\mathrm{Mg}^{2}+$ conditions (see diagrams) in heterotypic $\mathrm{Cx} 43 / \mathrm{CH} 3 \mathrm{GJs}(n=5)$. 
a
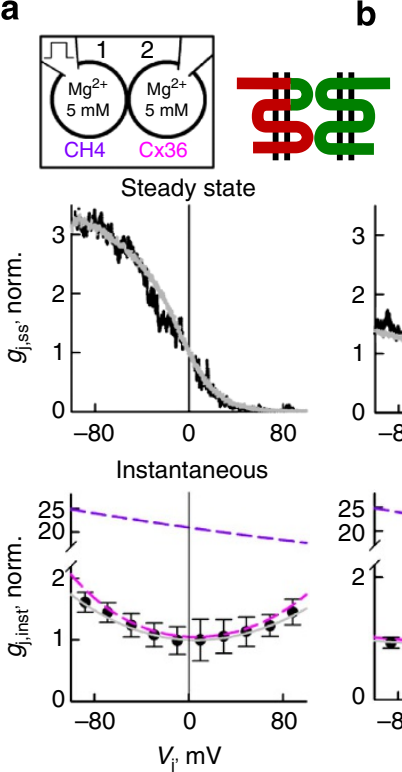

b

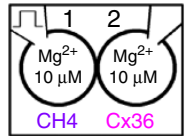

Steady state
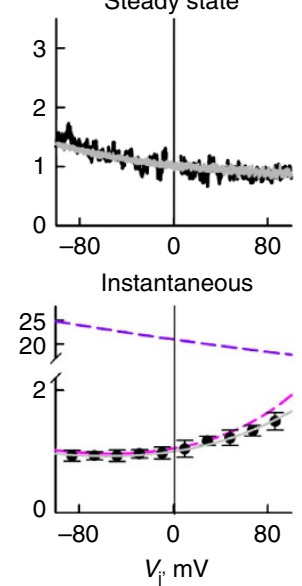

C
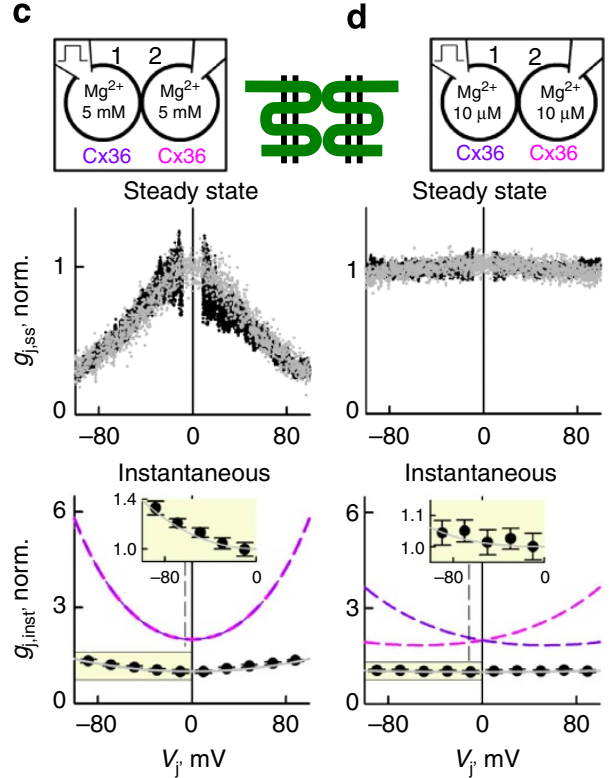

Figure 9 | $\mathbf{M g}^{2+}$-dependent asymmetry in steady-state and instantaneous $\boldsymbol{g}_{\mathbf{j}}-\boldsymbol{V}_{\mathbf{j}}$ relationship in $\mathbf{C x 3 6 / C H 4 ~ h e t e r o t y p i c ~} \mathbf{G J s}$. (a,b) Asymmetric steady-state (top) and instantaneous (bottom) $g_{\mathrm{j}}-V_{\mathrm{j}}$ relationships shown in black (normalized to $g_{\mathrm{j}}$ value at $V_{\mathrm{j}}=0$, and obtained using the same $V_{\mathrm{j}}$ protocol shown in Fig 6a,b, respectively) obtained under symmetric high (a) and low (b) $\left[\mathrm{Mg}^{2+}\right]_{\mathrm{p}}$ in heterotypic $\mathrm{Cx36/CH4} \mathrm{GJs}(n=5)$. The top diagram in each plot shows $\left[\mathrm{Mg}^{2+}\right]_{\mathrm{p}}$ used in cell-1 and cell-2, stimulation sites and expressed Cxs. Each data point for $g_{\mathrm{j}, \text { inst }}-V_{\mathrm{j}}$ relationships was obtained by averaging data from $\sim 10$ consecutive $V_{\mathrm{j}}$ protocols, and error bars correspond to s.e.m. Simulated curves shown in grey for steady-state (top) and instantaneous (bottom) $g_{\mathrm{j}}-V_{\mathrm{j}}$ relationships were obtained using the S4SM. Dotted lines show $g_{\mathrm{j}, \text { inst }}-V_{\mathrm{j}}$ relationships for $\mathrm{CH} 4$ (purple) and $\mathrm{Cx} 36$ (pink) aHCs used in simulation of steady-state and instantaneous $g_{j}-V_{j}$ relationships. (c,d) Symmetric steady-state (top) and instantaneous (bottom) $g_{j}-V_{j}$ relationships for homotypic Cx36 GJs are shown in black (data from Fig. 6c,d). Simulated curves shown in grey were obtained using the S4SM and similar rectification parameters were obtained from $\mathrm{C} \times 36$ aHCs shown in $\mathbf{a}$ and $\mathbf{b}$. All parameters for simulation are reported in Supplementary Table 1.

defined by: (1) asymmetry of fixed charges inside the Cx36 aHC pore, as described by Poisson-Nernst-Plank equations ${ }^{63}$; and (2) $\left[\mathrm{Mg}^{2+}\right]_{\mathrm{i}}$. Figure 10d (top) shows a family of simulated $g_{\mathrm{j}, \text { inst }}-V_{\mathrm{j}}$ plots for Cx36 aHCs using S4SM (details in the Results section), in which the rectification coefficient, $r_{\mathrm{H}}$, was constant and equal to $90 \mathrm{mV}$, and the $\mathrm{Mg}^{2+}$-dependent rectification coefficient, $r_{\mathrm{Mg}}$, changed from $\sim 200$ to $80 \mathrm{mV}$ when $\left[\mathrm{Mg}^{2+}\right]_{\mathrm{i}}$ increased from $\sim 0.01$ to $5 \mathrm{mM}$. Figure $10 \mathrm{~d}$ (bottom) shows simulated $g_{\mathrm{j} \text {,inst }}-V_{\mathrm{j}}$ plots of homotypic Cx36 GJs using the same parameters as for Cx36 aHCs. Thus, $\mathrm{Mg}^{2+}$-dependent rectification can explain the transformation of $g_{\mathrm{j}, \text { inst }}-V_{\mathrm{j}}$ dependence observed in heterotypic Cx36/CH4 (Fig. 9a,b) and homotypic Cx36 (Fig. 9c,d) GJs. Hyperbola-like conductance-voltage rectification has also been shown in a solid back-to-back $\mathrm{p}-\mathrm{n}$ junction ${ }^{64}$, but applicability of such junctions to GJ channels remains unclear. The $g_{\mathrm{j} \text {,inst }}-V_{\mathrm{j}}$ rectification was not observed under high or low $\left[\mathrm{Mg}^{2+}\right]_{\mathrm{i}}$ in $\mathrm{CH} 1$ GJs (Supplementary Fig. 7), suggesting that residues in the NT-M1 region of the Cx36 protein are necessary for instantaneous rectification.

To our knowledge, molecular mechanisms of electrical rectification in GJs have been examined only in heterotypic GJs. In this regard, two mechanisms have been proposed: differences in fast $V_{\mathrm{j}}$-dependent gating and gating polarity of aHCs of heterotypic GJs ${ }^{65,66}$; and/or rectification of the single-channel conductance resulting from an asymmetry in the number and position of charged residues inside the channel pore of heterotypic $\mathrm{GJs}^{6{ }^{6}}$. Thus, we propose that transjunctional asymmetry in $\left[\mathrm{Mg}^{2+}\right]_{\mathrm{i}}$ can serve as a novel mechanism for electrical rectification in homotypic GJs (Fig. 6e). It is important to note that the degree of rectification in electrical synapses has been proposed to affect the dynamic output of neuronal networks ${ }^{68}$, and therefore this novel instantaneous $\mathrm{Mg}^{2+}$. dependent rectification could be important to explain the phenomenon of switching between firing states and changes in the output of neuronal networks during different metabolic states where $\left[\mathrm{Mg}^{2+}\right]_{\mathrm{i}}$ is affected. Taken together, these findings suggest that changes in $\left[\mathrm{Mg}^{2+}\right]_{\mathrm{i}}$ may be sufficient to induce plasticity of Cx36-based electrical synaptic transmission.

\section{Methods}

Generation of $\mathbf{C H}$ and mutants. All $\mathrm{CH}$ were generated using a modified version of the 'sticky feet'-directed mutagenesis protocol ${ }^{48}$. Briefly, long PCR oligonucleotide primers that share a complementary sequence were used as forward or reverse primers to isolate fragments with complementary ends of two different genes (1st PCR step). Subsequently, these long DNA fragments were used as primer DNAs to produce chimeric fragments from two different genes (2nd PCR step). This protocol is illustrated in Supplementary Fig. 2. A total of 22 different DNA fragments with complementary ends (FX-1 and FX-2) were generated to produce 14 different chimeric fragments (FX; Supplementary Fig. 3). Two additional chimeric fragments (F12 and F16) were generated by restriction enzyme subcloning (Supplementary Fig. 3). A list of all primer sequences and restriction enzymes used in the generation of each DNA fragment is provided in Supplementary Table 2. Design of primers was assisted by Clone Manager Professional 9 (Sci-Ed software, NC, USA). Platinum PCR SuperMix High Fidelity (Life Technologies, NY, USA) were used for all PCRs. PCR products were separated by acrylamide gel electrophoresis and isolated with a gel extraction kit (Qiagen). All restriction enzymes were purchased from New England Biolabs. Amino acid substitutions in Cx36 and Cx43 were introduced using the Quickchange Multi Site-directed Mutagenesis Kit (Agilent, TX, USA) or ordered from Genscript (New Jersey, USA) using the site-directed mutagenesis service. $\mathrm{CH}$ and mutant fragments were subcloned into pEGFP-N1 (Clontech, CA, USA). All plasmid transfections were performed with Lipofectamine 2000 (Life Technologies, NY USA).

Cell lines and culture conditions. Experiments were performed in RIN cells (rat beta-cell insulinoma, ATCC CRL-2057) transfected with Cx36, Cx43, CH or mutants fused with colour variants of green fluorescent proteins (EGFP or CFP) attached to the CT. All experiments were performed with stable cell lines to minimize variability. All cell cultures were grown in RPMI 1640, with L-glutamine, supplemented with $8 \%$ fetal calf serum, $100 \mu \mathrm{g}$ per $\mathrm{ml}$ streptomycin and 100 units per $\mathrm{ml}$ penicillin, and maintained in a $\mathrm{CO}_{2}$ incubator $\left(37^{\circ} \mathrm{C}\right.$ and $\left.5 \% \mathrm{CO}_{2}\right)$. 


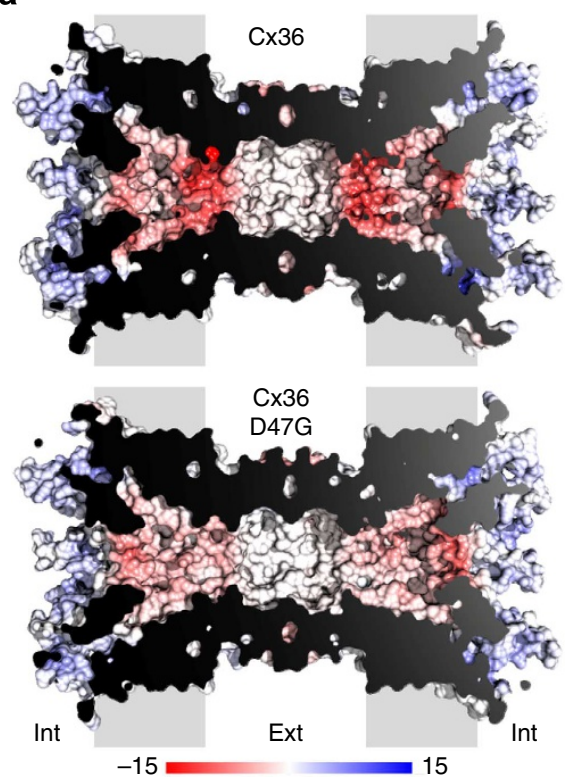

b

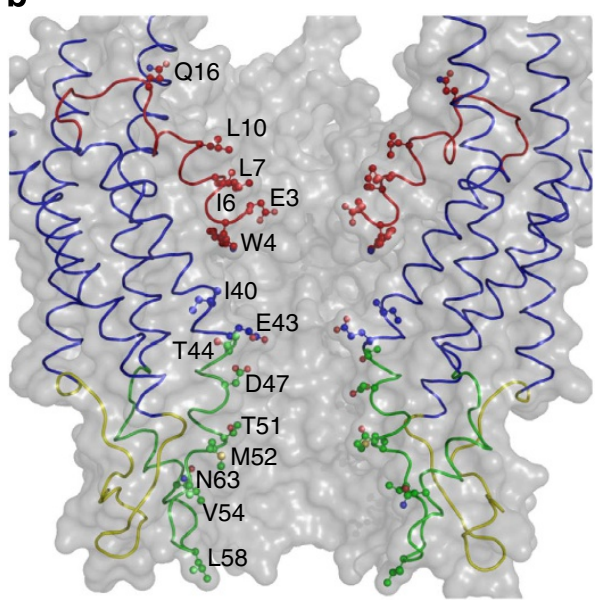

C

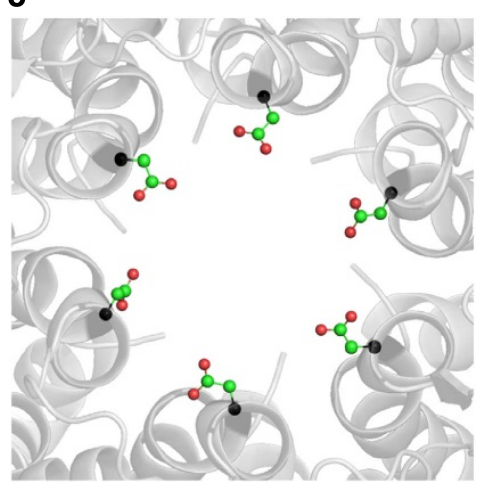

d
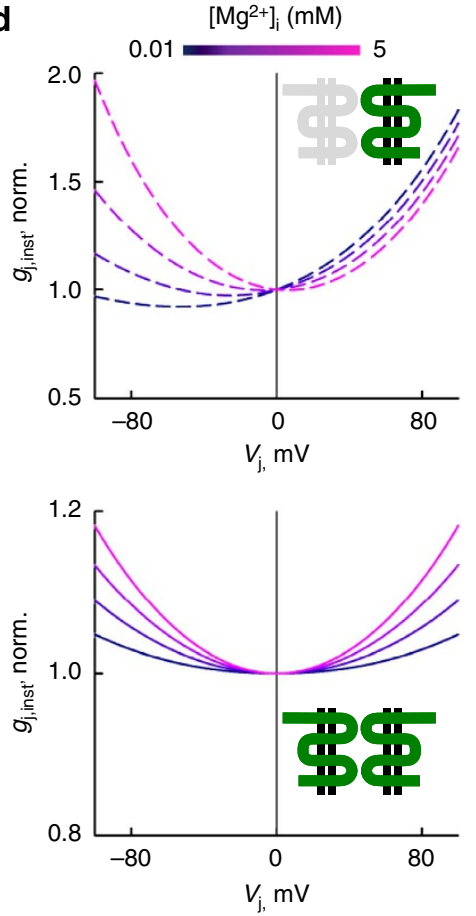

Figure 10 | Homology models of Cx36 and Cx36*D47G GJ channel structure and $\mathbf{M g}^{\mathbf{2}+}$-dependent modulation of instantaneous rectification.

(a) Cross-sections of GJ channels formed by Cx36 (top) or Cx36*D47G (bottom) generated by sequence homology to Cx26 crystal structure. Electrostatic surface potential is displayed for both channels and was estimated with DELPHI (see Methods). The colour bar at the bottom represents electrostatic surface potentials ranging from -15 (red) to 15 (blue) $k T e^{-1}$. (b) Side view of a $\mathrm{C} \times 36$ aHC indicating the pore-lining residues of only two $\mathrm{Cx}$ subunits represented with thin ribbon style (principal chain). Main domains of $\mathrm{Cx}$ subunits are depicted with different colours and the side chains of pore-lining residues are represented with sticks and spheres. (c) View of the pore from the centre of the channel towards the cytoplasmic mouth. The six D47 residues are displayed with sticks and spheres to illustrate the orientation and position of their side chains with respect to the lumen of the channel. (d) Normalized $g_{j, \text { inst }}-V_{j}$ plots for aHCs (top) and GJ channels (bottom) formed by $\mathrm{C} \times 36$ generated using different values for $\mathrm{Mg}^{2+}$-dependent coefficient $\left(r_{\mathrm{Mg}}\right)$ with the S4SM of GJ channels gating. Colour bar at the top represents different $\left[\mathrm{Mg}^{2+}\right]_{i}$ from 0.01 to $5 \mathrm{mM}$.

In vitro electrophysiology. Electrophysiological recordings were performed in cell cultures grown on glass coverslips and submerged on an experimental chamber mounted on the stage of an inverted IX70 microscope (Olympus) equipped with a fluorescence imaging system. Extracellular solution contained (in $\mathrm{mM}$ ): $140 \mathrm{NaCl}, 4 \mathrm{KCl}, 2 \mathrm{CaCl}_{2}, 1 \mathrm{MgCl}_{2}, 2 \mathrm{CsCl}, 1 \mathrm{BaCl}_{2}, 5$ glucose, 2 pyruvate and 5 HEPES ( $\mathrm{pH} 7.4$ adjusted with $\mathrm{NaOH})$. Standard pipette solution contained (in $\mathrm{mM}$ ): $130 \mathrm{CsCl}, 10 \mathrm{NaAsp}, 1 \mathrm{MgCl}_{2}, 0.26 \mathrm{CaCl}_{2}, 2$ EGTA and 5 HEPES ( $\mathrm{pH} 7.2$ adjusted with $\mathrm{CsOH}$ ). Resistance of recording pipettes was in the order of 3-5 M 2 . We used either EDTA or $\mathrm{MgCl}_{2}$ and the web-based Maxchelator software to adjust and calculate free $\mathrm{Mg}^{2}+$ concentration in the pipette solutions. Junctional conductance $\left(g_{\mathfrak{j}}\right)$ was measured using two EPC-8 patch clamp amplifiers (HEKA); briefly, a transjunctional voltage $\left(V_{\mathrm{j}}\right)$ was generated by modifying voltage in cell-1 $\left(V_{1}\right)$ and keeping the voltage in cell-2 $\left(V_{2}\right)$ constant $\left(V_{j}=\Delta V_{1}\right)$. Application of $V_{\mathrm{j}}$ induced a transjunctional current $\left(I_{\mathrm{j}}\right)$ of opposite polarity to $V_{\mathrm{j}}\left(I_{\mathrm{j}}=-\Delta I_{2}\right.$, and $\left.g_{\mathrm{j}}=I_{\mathrm{j}} / V_{\mathrm{j}}\right)$. Signals were digitized using an A/D converter (Axon instruments) and data were acquired and analysed using custom-made software.
Brain-slice preparation and electrophysiology. A minimal number of animals were killed in accordance with the National Institute of Health Guide for the Care and Use of Laboratory Animals, and with the provisions of the Institutional Animal Care and Use Committee of the Marine Biological Laboratory. Horizontal brain slices (300- $\mu \mathrm{m}$ thick) were prepared from the BAC transgenic mouse line $\mathrm{Tg}(\mathrm{Gj} d 2$ EGFP)JM16Gsat/Mmucd ${ }^{44}$, in which the expression of EGFP reporter gene is driven by the activity of the Cx36 promoter. Male or female mice age between P5 and P15 were used. Brain slices were obtained using a chilled VT1200 blade vibrating microtome (Leica Biosystems, IL, USA) and sliced in cold sucrose solution containing (in mM): 238 sucrose, $2.7 \mathrm{KCl}, 1.25 \mathrm{KH}_{2} \mathrm{PO}_{4}, 26 \mathrm{NaHCO}_{3}$ 11 Glucose, $2 \mathrm{CaCl}_{2}$ and $2 \mathrm{MgSO}_{4}$. Brain slices were transferred to an incubation chamber with extracellular recording solution and incubated for $20 \mathrm{~min}$ at $37^{\circ} \mathrm{C}$. The extracellular recording solution contained (in $\mathrm{mM}$ ): $124 \mathrm{NaCl}, 2.7 \mathrm{KCl}, 1.25$ $\mathrm{KH}_{2} \mathrm{PO}_{4}, 26 \mathrm{NaHCO}_{3}, 10$ Glucose, $2 \mathrm{CaCl}_{2}$ and $2 \mathrm{MgSO}_{4}$. The incubation chamber was then kept at room temperature for 30-40 min before electrophysiology. Brain slices were then transferred to a low-noise RC-27LD recording chamber (Warner Instruments, Hamden, CT) mounted on an Axio Examiner A1 microscope 
(Zeiss, Thornwood, NY) equipped with an Orca-R2 digital camera (Hamamatsu, Bridgewater, NJ) for infrared differential interference contrast (IR-DIC) and fluorescence imaging. Extracellular recording solution was continuously exchanged $(\sim 2 \mathrm{ml}$ per $\mathrm{min})$ at room temperature in the chamber by a gravity feed perfusion system. All sucrose and extracellular solutions were constantly bubbled and saturated with carbogen $\left(95 \%\right.$ oxygen $\left./ 5 \% \mathrm{CO}_{2}\right)$ throughout the slice procedure and electrophysiology experiments. TRN neurons were identified based on characteristic location, cell shape and electrophysiological properties ${ }^{45}$. A standard pipette solution contained (in mM): $120 \mathrm{~K}$-Gluconate, $20 \mathrm{KCl}, 2 \mathrm{MgCl}_{2}, 0.2 \mathrm{EGTA}$, and 10 HEPES ( $\mathrm{pH} 7.2$ adjusted with KOH). Resistance of recording pipettes was on the order of 6-10 M $\Omega$. We used $\mathrm{K}_{2} \mathrm{ATP}$ or MgATP to decrease or increase, respectively, free $\mathrm{Mg}^{2+}$ concentration in the pipette solutions ${ }^{2,43}$. Changes in membrane voltage and current were measured using two separate Axopatch 200B amplifiers, digitized using a Digidata 1,440A, and acquired and analysed using pClamp 10 software (Molecular Devices, Sunnyvale, CA). The $g_{\mathrm{j}}$ was measured and calculated as explained for the in vitro electrophysiology (see above).

\section{Confocal microscopy and fluorescence imaging. Fluorescence signals from} EGFP expression in acute TRN brain slices were acquired using a LSM-780 Quasar confocal system configured on an inverted Observer Z1 microscope. Imaging during electrophysiology studies was conducted using an Axio Examiner A1 microscope (Zeiss, Oberkochen, Germany) equipped with an Orca-R2 digital camera (Hamamatsu Corp., Bridgewater, NJ). Image acquisition and processing were performed using ZEN software (Zeiss, Oberkochen, Germany). For in vitro studies, fluorescence signals from EGFP or CFP were acquired using an IX70 microscope (Olympus, USA) equipped with an ORCA-R2 digital camera (Hamamatsu Corp., Bridgewater, NJ). Image acquisition and processing were performed using UltraVIEW software (Perkin Elmer Life Sciences, Boston, MA).

Homology models and electrostatic surface potential. Structural homology models of $\mathrm{Cx} 36$ and $\mathrm{Cx} 36^{*} \mathrm{D} 47 \mathrm{G}$ were built using the known three-dimensional structure of $\mathrm{C} \times 26$ as a template ${ }^{55}$. The corresponding Cx26 cytoplasmic loop and $\mathrm{C}$ terminus domains of $\mathrm{Cx} 36$ were deleted, and the target-template alignment was selected by hand, scoring a sequence identity of $47 \%$. On the basis of this alignment, 200 models were generated by means of the MODELLER program and the best model was selected according to the DOPE score ${ }^{69}$. The electrostatic potential on the solvent accessible surface (surface potential) of the structural homology models was estimated using DELPHI, which provides finite difference solutions to the Poisson-Boltzmann equation ${ }^{70}$. Surface potentials are displayed according to the averaged electrostatic potential found at the surface of the $\mathrm{Cx}$ accesible to the solvent. Default dielectric constants of 2.0 for interior (protein) and 80.0 for exterior (solvent) regions were used.

Data analysis. The analysis and statistics were performed using SigmaPlot v10 (Systat Software Inc, Chicago, IL) and pClamp 10 (Molecular Devices). Averaged data are reported as the means \pm s.e.m. Means for each group were compared using an unpaired Student's $t$-test.

\section{References}

1. Masuda, T., Dobson, G. P. \& Veech, R. L. The Gibbs-Donnan near-equilibrium system of heart. J. Biol. Chem. 265, 20321-20334 (1990).

2. Luthi, D., Gunzel, D. \& McGuigan, J. A. Mg-ATP binding: its modification by spermine, the relevance to cytosolic $\mathrm{Mg}^{2}+$ buffering, changes in the intracellular ionized $\mathrm{Mg}^{2}+$ concentration and the estimation of $\mathrm{Mg}^{2+}$ by 31P-NMR. Exp. Physiol. 84, 231-252 (1999).

3. Taylor, J. S. et al. Free magnesium levels in normal human brain and brain tumors: $31 \mathrm{P}$ chemical-shift imaging measurements at 1.5T. Proc. Natl Acad. Sci. USA 88, 6810-6814 (1991).

4. Chen, C., Nakatani, K. \& Koutalos, Y. Free magnesium concentration in salamander photoreceptor outer segments. J. Physiol. 553, 125-135 (2003).

5. Henrich, M. \& Buckler, K. J. Effects of anoxia, aglycemia, and acidosis on cytosolic $\mathrm{Mg}^{2+}, \mathrm{ATP}$, and $\mathrm{pH}$ in rat sensory neurons. Am. J. Physiol. Cell Physiol. 294, 280-294 (2008).

6. Kato, H., Gotoh, H., Kajikawa, M. \& Suto, K. Depolarization triggers intracellular magnesium surge in cultured dorsal root ganglion neurons. Brain Res. 779, 329-333 (1998).

7. Cheng, C. \& Reynolds, I. J. Subcellular localization of glutamate-stimulated intracellular magnesium concentration changes in cultured rat forebrain neurons using confocal microscopy. Neuroscience 95, 973-979 (2000).

8. Shindo, Y., Fujimoto, A., Hotta, K., Suzuki, K. \& Oka, K. Glutamate-induced calcium increase mediates magnesium release from mitochondria in rat hippocampal neurons. J. Neurosci. Res. 88, 3125-3132 (2010).

9. Yamanaka, R., Shindo, Y., Hotta, K., Suzuki, K. \& Oka, K. NO/cGMP/PKG signaling pathway induces magnesium release mediated by mitoKATP channel opening in rat hippocampal neurons. FEBS Lett. 587, 2643-2648 (2013).

10. Dworak, M., McCarley, R. W., Kim, T., Kalinchuk, A. V. \& Basheer, R. Sleep and brain energy levels: ATP changes during sleep. J. Neurosci. 30, 9007-9016 (2010).
11. Ainscow, E. K., Mirshamsi, S., Tang, T., Ashford, M. L. \& Rutter, G. A. Dynamic imaging of free cytosolic ATP concentration during fuel sensing by rat hypothalamic neurones: evidence for ATP-independent control of ATP-sensitive $\mathrm{K}(+)$ channels. J. Physiol. 544, 429-445 (2002).

12. Sims, N. R. \& Muyderman, H. Mitochondria, oxidative metabolism and cell death in stroke. Biochim. Biophys. Acta 1802, 80-91 (2010).

13. Williams, G. D. \& Smith, M. B. Application of the accurate assessment of intracellular magnesium and $\mathrm{pH}$ from the $31 \mathrm{P}$ shifts of ATP to cerebral hypoxia-ischemia in neonatal rat. Mag. Res. Med. 33, 853-857 (1995).

14. Zhang, J. et al. Hypoxia induces an increase in intracellular magnesium via transient receptor potential melastatin 7 (TRPM7) channels in rat hippocampal neurons in vitro. J. Biol. Chem. 286, 20194-20207 (2011).

15. Hinsberger, A. D. et al. Magnetic resonance imaging volumetric and phosphorus 31 magnetic resonance spectroscopy measurements in schizophrenia. J. Psychiatry Neurosci. 22, 111-117 (1997).

16. Cernak, I., Radosevic, P., Malicevic, Z. \& Savic, J. Experimental magnesium depletion in adult rabbits caused by blast overpressure. Magnes. Res. 8, 249-259 (1995).

17. Suzuki, M. et al. Decrease in cerebral free magnesium concentration following closed head injury and effects of VA-045 in rats. Gen. Pharmacol. 28, 119-121 (1997).

18. Oyanagi, K. et al. Magnesium deficiency over generations in rats with special references to the pathogenesis of the Parkinsonism-dementia complex and amyotrophic lateral sclerosis of Guam. Neuropathology 26, 115-128 (2006).

19. Andrasi, E., Igaz, S., Molnar, Z. \& Mako, S. Disturbances of magnesium concentrations in various brain areas in Alzheimer's disease. Magnes. Res. 13, 189-196 (2000).

20. Stelmasiak, Z., Solski, J. \& Jakubowska, B. Magnesium concentration in plasma and erythrocytes in MS. Acta Neurol. Scand. 92, 109-111 (1995).

21. Yasui, M., Yase, Y., Kihira, T., Adachi, K. \& Suzuki, Y. Magnesium and calcium contents in CNS tissues of amyotrophic lateral sclerosis patients from the Kii peninsula, Japan. Euro. Neurol. 32, 95-98 (1992).

22. Lodi, R. et al. Deficit of brain and skeletal muscle bioenergetics and low brain magnesium in juvenile migraine: an in vivo 31P magnetic resonance spectroscopy interictal study. Pediatr. Res. 42, 866-871 (1997).

23. Barbiroli, B. et al. Low brain intracellular free magnesium in mitochondrial cytopathies. J. Cereb. Blood Flow Metab. 19, 528-532 (1999).

24. Bennett, M. V. \& Zukin, R. S. Electrical coupling and neuronal synchronization in the mammalian brain. Neuron 41, 495-511 (2004).

25. Bissiere, S. et al. Electrical synapses control hippocampal contributions to fear learning and memory. Science 331, 87-91 (2011).

26. Yaksi, E. \& Wilson, R. I. Electrical coupling between olfactory glomeruli. Neuron 67, 1034-1047 (2010).

27. Bukauskas, F. F. \& Weingart, R. Voltage-dependent gating of single gap junction channels in an insect cell line. Biophys. J. 67, 613-625 (1994).

28. Palacios-Prado, N. \& Bukauskas, F. F. Heterotypic gap junction channels as voltage-sensitive valves for intercellular signaling. Proc. Natl Acad. Sci. USA 106, 14855-14860 (2009).

29. Palacios-Prado, N. \& Bukauskas, F. F. Modulation of metabolic communication through gap junction channels by transjunctional voltage; synergistic and antagonistic effects of gating and ionophoresis. Biochim. Biophys. Acta 1818, 1884-1894 (2012).

30. Furshpan, E. J. \& Potter, D. D. Transmission at the giant motor synapses of the crayfish. J. Physiol. 145, 289-325 (1959).

31. Auerbach, A. A. \& Bennett, M. V. L. A rectifying electrotonic synapse in the central nervous system of a vertebrate. J. Gen. Physiol. 53, 211-237 (1969).

32. Phelan, P. et al. Molecular mechanism of rectification at identified electrical synapses in the Drosophila giant fiber system. Curr. Biol. 18, 1955-1960 (2008).

33. Rash, J. E. et al. Molecular and functional asymmetry at a vertebrate electrical synapse. Neuron 79, 957-969 (2013).

34. Sohl, G., Maxeiner, S. \& Willecke, K. Expression and functions of neuronal gap junctions. Nat. Rev. Neurosci. 6, 191-200 (2005).

35. Connors, B. W. \& Long, M. A. Electrical synapses in the mammalian brain. Annu. Rev. Neurosci. 27, 393-418 (2004).

36. Ouyang, X. et al. Protein kinase A mediates regulation of gap junctions containing connexin35 through a complex pathway. Brain Res. Mol. Brain Res. 135, 1-11 (2005).

37. Alev, C. et al. The neuronal connexin 36 interacts with and is phosphorylated by CaMKII in a way similar to CaMKII interaction with glutamate receptors. Proc. Natl Acad. Sci. USA 105, 20964-20969 (2008).

38. González-Nieto, D. et al. Regulation of neuronal connexin-36 channels by $\mathrm{pH}$. Proc. Natl Acad. Sci. USA 105, 17169-17174 (2008).

39. Marandykina, A., Palacios-Prado, N., Rimkute, L., Skeberdis, V. A. \& Bukauskas, F. F. Regulation of connexin-36 gap junction channels by n-alkanols and arachidonic acid. J. Physiol. 591, 2087-2101 (2013).

40. Haas, J. S., Zavala, B. \& Landisman, C. E. Activity-dependent long-term depression of electrical synapses. Science 334, 389-393 (2011). 
41. Pereda, A. E. et al. $\mathrm{Ca}^{2+} /$ calmodulin-dependent kinase II mediates simultaneous enhancement of gap-junctional conductance and glutamatergic transmission. Proc. Natl Acad. Sci. USA 95, 13272-13277 (1998).

42. Cachope, R., Mackie, K., Triller, A., O’Brien, J. \& Pereda, A. E. Potentiation of electrical and chemical synaptic transmission mediated by endocannabinoids. Neuron 56, 1034-1047 (2007).

43. Palacios-Prado, N. et al. Intracellular magnesium-dependent modulation of gap junction channels formed by neuronal connexin36. J. Neurosci. 33, 4741-4753 (2013).

44. Gong, S. et al. A gene expression atlas of the central nervous system based on bacterial artificial chromosomes. Nature 425, 917-925 (2003).

45. Landisman, C. E. et al. Electrical synapses in the thalamic reticular nucleus. J. Neurosci. 22, 1002-1009 (2002).

46. Pinault, D. The thalamic reticular nucleus: structure, function and concept. Brain Res. Brain Res. Rev. 46, 1-31 (2004).

47. Bukauskas, F. F. et al. Clustering of connexin 43 -enhanced green fluorescent protein gap junction channels and functional coupling in living cells. Proc. Natl Acad. Sci. USA 97, 2556-2561 (2000).

48. Clackson, T. \& Winter, G. 'Sticky feet'-directed mutagenesis and its application to swapping antibody domains. Nucleic Acids Res. 17, 10163-10170 (1989).

49. Srinivas, M. et al. Functional properties of channels formed by the neuronal gap junction protein connexin36. J. Neurosci. 19, 9848-9855 (1999).

50. Moreno, A. P., Berthoud, V. M., Perez-Palacios, G. \& Perez-Armendariz, E. M. Biophysical evidence that connexin-36 forms functional gap junction channels between pancreatic mouse beta-cells. Am. J. Physiol. Endocrinol. Metab. 288, 948-956 (2005)

51. Rash, J. E., Yasumura, T., Dudek, F. E. \& Nagy, J. I. Cell-specific expression of connexins and evidence of restricted gap junctional coupling between glial cells and between neurons. J. Neurosci. 21, 1983-2000 (2001).

52. Bukauskas, F. F. \& Verselis, V. K. Gap junction channel gating. Biochim. Biophys. Acta 1662, 42-60 (2004).

53. Palacios-Prado, N. et al. $\mathrm{pH}$-dependent modulation of voltage gating in connexin 45 homotypic and connexin45/connexin 43 heterotypic gap junctions. Proc. Natl Acad. Sci. USA 107, 9897-9902 (2010).

54. Paulauskas, N., Pranevicius, M., Pranevicius, H. \& Bukauskas, F. F. A stochastic four-state model of contingent gating of gap junction channels containing two "fast" gates sensitive to transjunctional voltage. Biophys. J. 96, 3936-3948 (2009).

55. Maeda, S. et al. Structure of the connexin 26 gap junction channel at 3.5A resolution. Nature 458, 597-602 (2009).

56. Zonta, F. et al. Role of gamma carboxylated Glu47 in connexin 26 hemichannel regulation by extracellular Ca: Insight from a local quantum chemistry study. Biochem. Biophys. Res. Commun. 445, 10-15 (2014).

57. Musa, H. et al. Amino terminal glutamate residues confer spermine sensitivity and affect voltage gating and channel conductance of rat connexin40 gap junctions. J. Physiol. 557, 863-878 (2004).

58. Bukauskas, F. F., Bukauskiene, A., Bennett, M. V. L. \& Verselis, V. K. Gating properties of gap junction channels assembled from connexin 43 and connexin43 fused with green fluorescent protein. Biophys. J. 81, 137-152 (2001).

59. White, T. W., Bruzzone, R., Wolfram, S., Paul, D. L. \& Goodenough, D. A. Selective interactions among the multiple connexin proteins expressed in the vertebrate lens: the second extracellular domain is a determinant of compatibility between connexins. J. Cell Biol. 125, 879-892 (1994).

60. Nakagawa, S. et al. Asparagine 175 of connexin32 is a critical residue for docking and forming functional heterotypic gap junction channels with connexin26. J. Biol. Chem. 286, 19672-19681 (2011)
61. Ramanan, S. V. et al. A three-state model for connexin37 gating kinetics. Biophys. J. 76, 2520-2529 (1999).

62. Teubner, B. et al. Functional expression of the murine connexin 36 gene coding for a neuron-specific gap junctional protein. J. Membr. Biol. 176, 249-262 (2000).

63. Oh, S., Rivkin, S., Tang, Q., Verselis, V. K. \& Bargiello, T. A. Determinants of gating polarity of a connexin 32 hemichannel. Biophys. J. 87, 912-928 (2004).

64. Chiquito, A. J. et al. Back-to-back Schottky diodes: the generalization of the diode theory in analysis and extraction of electrical parameters of nanodevices. J. Phys. Condens. Matter 24, 225303 (2012).

65. Jaslove, S. W. \& Brink, P. R. The mechanism of rectification at the electrotonic motor giant synapse of the crayfish. Nature 323, 63-65 (1986).

66. Verselis, V. K., Ginter, C. S. \& Bargiello, T. A. Opposite voltage gating polarities of two closely related connexins. Nature 368, 348-351 (1994).

67. Oh, S., Rubin, J. B., Bennett, M. V., Verselis, V. K. \& Bargiello, T. A. Molecular determinants of electrical rectification of single channel conductance in gap junctions formed by connexins 26 and 32. J. Gen. Physiol. 114, 339-364 (1999).

68. Gutierrez, G. J. \& Marder, E. Rectifying electrical synapses can affect the influence of synaptic modulation on output pattern robustness. J. Neurosci. 33, 13238-13248 (2013)

69. Eswar, N., Eramian, D., Webb, B., Shen, M. Y. \& Sali, A. Protein structure modeling with MODELLER. Methods Mol. Biol. 426, 145-159 (2008).

70. Rocchia, W. et al. Rapid grid-based construction of the molecular surface and the use of induced surface charge to calculate reaction field energies: applications to the molecular systems and geometric objects. J. Comput. Chem. 23, 128-137 (2002)

\section{Acknowledgements}

We thank Michael V.L. Bennett, Vytautas K. Verselis and Thaddeus A. Bargiello for helpful comments and discussions. We thank Nerijus Paulauskas for assistance with S4SM, and Angele Bukauskiene and Alis Dicpinigaitis for excellent technical assistance. We thank Jim McIlvain and Elizabeth Dille from Zeiss for assistance with confocal imaging. Nicolás Palacios-Prado is a Howard Hughes Medical Institute International Student Research Fellow. This work was supported by the Grass Foundation with a Grass Fellowship to N.P-P., by a grant from the Canadian Institute of Health Research to J.I.N. and by the National Institute of Health grant R01NS 072238 to F.F.B.

\section{Author contributions}

N.P.-P. and F.F.B. conceived and designed the experiments. N.P.-P., S.C., J.F. and F.F.B. performed the experiments and analysed the data. A.P. and J.I.N contributed reagents/materials/analysis tools and critically revised the paper. N.P.-P. and F.F.B. coordinated the study and wrote the paper.

\section{Additional information}

Supplementary Information accompanies this paper at http://www.nature.com/ naturecommunications

Competing financial interests: The authors declare no competing financial interests.

Reprints and permission information is available online at http://npg.nature.com/ reprintsandpermissions/

How to cite this article: Palacios-Prado, N. et al. Molecular determinants of magnesium-dependent synaptic plasticity at electrical synapses formed by connexin 36 . Nat. Commun. 5:4667 doi: 10.1038/ncomms5667 (2014). 